J Am Chem Soc. 2017 February 08; 139(5): 1900-1911. doi:10.1021/jacs.6b11324.

\title{
A Structure-Based Mechanism for Oxidative Decarboxylation Reactions Mediated by Amino Acids and Heme Propionates in Coproheme Decarboxylase (HemQ)
}

\author{
Arianna I. Celis ${ }^{1}$, George H. Gauss ${ }^{1}$, Bennett R. Streit ${ }^{1}$, Krista Shisler ${ }^{1}$, Garrett C. Moraski ${ }^{1}$, \\ Kenton R. Rodgers ${ }^{2}$, Gudrun S. Lukat-Rodgers ${ }^{2}$, John W. Peters ${ }^{1}$, and Jennifer L. DuBois ${ }^{1,{ }^{*}}$ \\ ${ }^{1}$ Department of Chemistry and Biochemistry, Montana State University, Bozeman, MT \\ $59717-3400$ \\ ${ }^{2}$ Department of Chemistry and Biochemistry, North Dakota State University, Fargo, ND \\ $58108-6050$
}

\begin{abstract}
Coproheme decarboxylase catalyzes two sequential oxidative decarboxylations with $\mathrm{H}_{2} \mathrm{O}_{2}$ as the oxidant, coproheme III as substrate and cofactor, and heme $b$ as the product. Each reaction breaks a C-C bond and results in net loss of hydride, via steps that are not clear. Solution and solid-state structural characterization of the protein in complex with a substrate analog revealed a highly unconventional $\mathrm{H}_{2} \mathrm{O}_{2}$-activating distal environment with the reactive propionic acids ( 2 and 4 ) on the opposite side of the porphyrin plane. This suggested that, in contrast to direct $\mathrm{C}-\mathrm{H}$ bond cleavage catalyzed by a high-valent iron intermediate, the coproheme oxidations must occur through mediating amino acid residues. A tyrosine that hydrogen bonds to propionate 2 in a position analogous to the substrate in ascorbate peroxidase is essential for both decarboxylations, while a lysine that salt bridges to propionate 4 is required solely for the second. A mechanism is proposed in which propionate 2 relays an oxidizing equivalent from a coproheme compound I intermediate to the reactive deprotonated tyrosine, forming Tyr $\boldsymbol{\square}$. This residue then abstracts a net hydrogen atom $(\mathrm{H} \mathbf{n})$ from propionate 2, followed by migration of the unpaired propionyl electron to the coproheme iron to yield the ferric harderoheme and $\mathrm{CO}_{2}$ products. A similar pathway is proposed for decarboxylation of propionate 4 , but with a lysine residue as an essential proton shuttle. The proposed reaction suggests an extended relay of heme-mediated $\mathrm{e}^{-} / \mathrm{H}^{+}$transfers and a novel route for the conversion of carboxylic acids to alkenes.
\end{abstract}

\section{Graphical abstract}

\footnotetext{
*Corresponding Author: jennifer.dubois1@ montana.edu, Department of Chemistry and Biochemistry, Montana State University, Bozeman, MT 59717.

Author Contributions

The manuscript was written through contributions of all authors.

All authors have given approval to the final version of the manuscript.

Supporting Information.

A series of 15 data figures and 4 tables is included. This material is available free of charge via the Internet at http://pubs.acs.org.
} 


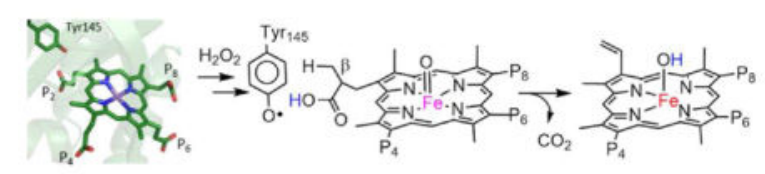

\section{Keywords}

heme $b$; propionate; tyrosyl; decarboxylation

\section{INTRODUCTION}

Activation of $\mathrm{O}_{2}$ or $\mathrm{H}_{2} \mathrm{O}_{2}$ by heme often leads to the generation of high-valent iron-oxo (ferryl) intermediates. ${ }^{1}$ In reactions catalyzed by heme peroxidases, donation of two electrons from the $\mathrm{Fe}(\mathrm{III})$-porphyrin complex results in heterolytic cleavage of the $\mathrm{HO}-\mathrm{OH}$ bond. The resulting compound I intermediate carries one oxidizing equivalent on the iron and the other in the porphyrin $\pi$ system, and is consequently described as $\mathrm{Fe}(\mathrm{IV})=\mathrm{O}$ coupled to a porphyrin radical cation (por + +): 2,3

$$
\mathrm{Fe}(\mathrm{III}) \text { por }+\mathrm{H}_{2} \mathrm{O}_{2} \rightarrow \mathrm{Fe}(\mathrm{IV})=\mathrm{O}(\text { por } \bullet+)+\mathrm{H}_{2} \mathrm{O}
$$

How this central intermediate forms and how it oxidizes compounds, sometimes over long distances, are longstanding questions in catalysis research. In reactions catalyzed by many cytochrome P450s and peroxidases, ${ }^{4} 1 \mathrm{e}-+1 \mathrm{H}^{+}$are transferred from a substrate to compound I. Such reactions, known as proton coupled electron transfers, ${ }^{5}$ can occur in a single concerted proton/electron transfer step. Alternatively, as in the catalytic model for $\mathrm{P} 450 \mathrm{~s},{ }^{3}$ the proton may migrate to the ferryl oxygen while the electron enters an orbital that is porphyrin-based. The overall reaction is described as hydrogen atom transfer. ${ }^{6}$

The proton and electron may have distinct routes to their separate destinations, though in only few cases have these been rigorously described. In ascorbate peroxidase (APX), the ascorbate substrate binds near and donates a hydrogen bond (H-bond) to one of the heme propionates (Fig. S1). ${ }^{7} 8$ Hydrogen atom transfer from ascorbate, in both APX and a synthetic heme complex designed to mimic it, ${ }^{9}$ occurs with the propionate acting both as a base toward the proton and as the conduit for the electron to por + . The proton is shuttled to an active site arginine and water molecules before finally arriving at the ferryl oxygen, ${ }^{10}$ and the resulting $\mathrm{Fe}(\mathrm{IV})=\mathrm{O}+\mathrm{H}^{+}$or $\mathrm{Fe}(\mathrm{IV})-\mathrm{OH}$ complex is known as compound $\mathrm{II}^{11}{ }^{11}$ Transfer of a hydrogen atom from a second substrate leads back to the ferric heme and a molecule of water. Representing the substrate as SH gives the general reaction scheme:

$$
\mathrm{Fe}(\mathrm{IV})=\mathrm{O}(\text { por } \bullet+)+\mathrm{SH} \rightarrow \mathrm{Fe}(\mathrm{IV})-\mathrm{OH}(\text { por })+\mathrm{S} \bullet
$$




$$
\mathrm{Fe}(\mathrm{IV})-\mathrm{OH}(\text { por })+\mathrm{SH} \rightarrow \mathrm{Fe}(\mathrm{III})(\text { por })+\mathrm{H}_{2} \mathrm{O}+\mathrm{S} \bullet
$$

The propionate in APX (Fig. S1) allows the heme to transmit oxidizing equivalents, from the site where the heme iron converts $\mathrm{H}_{2} \mathrm{O}_{2}$ to its catalytically activated compound I form, to the substrate binding site. In some peroxidases, including cytochrome $c$ peroxidase $(\mathrm{CCP})$ and lignin peroxidase (LnP), ${ }^{12-14}$ the sites of heme- $\mathrm{Fe}(\mathrm{III}) / \mathrm{H}_{2} \mathrm{O}_{2}$ reaction and substrate oxidation may be quite spatially remote. Redox-active amino acid side chains ${ }^{15-17}$ in addition to the propionates ${ }^{18}$ act as internal mediators within these enzymes. These supply the means to move oxidizing equivalents away from por + and to the site where substrates bind, greatly extending the catalytic reach of heme as an oxidation catalyst.

Here, we describe the combined structural and solution-state characterization of a $\mathrm{H}_{2} \mathrm{O}_{2}$ activating heme protein in which the iron and the pair of organic substrates have an unusual spatial and electronic relationship. The enzyme uses $\mathrm{H}_{2} \mathrm{O}_{2}$ as an oxidant in the successive decarboxylations of propionates 2 and 4 of iron coproporphyrin III (coproheme), which serves as both substrate and cofactor in the reactions (Scheme 1). Use of $\mathrm{H}_{2} \mathrm{O}_{2}$ as the biological oxidant in a decarboxylation or indeed any $\mathrm{C}-\mathrm{C}$ bond cleavage is a highly uncommon feature of this enzyme, ${ }^{19}$ which is encoded by the hemQ gene and which is responsible for the last step in heme biosynthesis in many gram positive bacteria. ${ }^{20}$ The 1.8 A resolution structure of the protein in complex with its $\mathrm{Mn}(\mathrm{III})$-containing substrate analog clearly shows the two reactive propionates residing below the coproheme plane, in a position where they cannot directly make contact with a ferryl intermediate. Instead, the structure suggests and the solution data support an electron/proton relay involving the heme, its propionates, and reactive amino acid side chains, leading to net transfers of an electron and a hydrogen atom from the reactive propionates themselves. The structurally-inferred, experimentally supported reaction mechanism is unprecedented in biology. As such, it suggests possible new avenues for extending the catalytic repertoire of synthetic heme complexes.

\section{EXPERIMENTAL PROCEDURES}

\section{Expression, purification, and ligand binding to WT and mutant coproheme decarboxylases}

The sequence of the protein encoded by the hemQ from Geobacillus stearothermophilus (Gs, NCBI accession WP_053414189, PDB ID: 1T0T) ${ }^{23}$ was used to design a codon-optimized synthetic hem $Q$ gene for expression in untagged form in Escherichia coli. The gene was inserted into a pET14(a) plasmid between the Nde1 and Xho1 restriction sites and used to transform competent E. coli Tuner (DE3) cells (Novagen). A similar construct for expressing the untagged, homologous protein from Staphylococcus aureus ( $\mathrm{Sa}$ ) was previously described. ${ }^{21}$ A QuikChange Lightning Site-Directed Mutagenesis Kit (Agilent) was used to generate site-directed mutants of $S a$ decarboxylase using the manufacturer's instructions and primers in Table S1. For residues closer to the protein interior, substitutions were made from Tyr/Ser, or Trp/Phe- in order to retain the hydrophobic/hydrophilic character of the WT residue while dramatically changing its size or chemical functionality. Residues at the solvent interface were substituted by Ala. 
Proteins were overexpressed and isolated at $>95 \%$ purity by reverse-anion exchange and gel filtration chromatography as previously described. ${ }^{21}$ Concentrated proteins (Amicon, 10,000 MWCO centrifuge filters) were incubated in the dark with gentle stirring at $4{ }^{\circ} \mathrm{C}$ for $24 \mathrm{~h}$ with either the substrate ferric coproheme III or the substrate analog Mn(III) coproporphyrinate III (coproporphyrinate III = tetrakis-2,4,6,7-propionate-protoporphyrin, Frontier Scientific) in a 1:1 subunit: coproheme ratio. Unbound coproheme was removed and the protein-ligand complexes further purified on an S-200 Sephacryl gel filtration column $(0.4 \mathrm{ml} / \mathrm{min})$. Fractions were collected using an AKTA purification system and then screened via UV/Vis spectroscopy (Cary50) for coproheme content. Fractions with Rz values $\searrow 0.8(\mathrm{Rz}=$ absorbance So-ret/absorbance $280 \mathrm{~nm})$ were pooled. The Bradford and pyridine hemochrome assays for protein and released coproheme, respectively, were used to determine the coproheme occupancy in the purified complexes. Extinction coefficients determined for the $G s$ coproheme decarboxylase complexes were $\varepsilon$ Soret $=110.6 \mathrm{mM}^{-1}$ $\mathrm{cm}^{-1}$ (Fe-coproheme) ${ }^{21}$ and $\varepsilon$ Soret $=69.7 \pm 6.6 \mathrm{mM}^{-1} \mathrm{~cm}^{-1}$ (Mn-coproheme) (Fig. S2).

\section{Structure Determination}

The $G s$ decarboxylase in complex with $\mathrm{Mn}(\mathrm{III})$ coproheme was crystallized by hanging drop vapor diffusion at $20^{\circ} \mathrm{C}$. Drops were assembled by mixing the complex $(7 \mathrm{mg} / \mathrm{mL}$ in $10 \mathrm{mM}$ HEPES-NaOH pH 7.5) with an equal volume of reservoir solution (0.1 M citrate $\mathrm{pH} 5.0$ $5.5,15-25 \%$ (w/v) polyethylene glycol 3350). Bright red crystals of the complex formed after approximately 2 weeks. Crystals were briefly soaked in reservoir solution supplemented with $15 \%(\mathrm{w} / \mathrm{v})$ glycerol as a cryoprotectant prior to freezing in liquid $\mathrm{N}_{2}$. An $\mathrm{X}$-ray diffraction dataset to 1.8 A was measured at Stanford Synchrotron Radiation Lightsource beamline 14-1 and processed with autoxds. ${ }^{24}$ The structure was determined by molecular replacement using Phaser ${ }^{25}$ in the CCP4 program suite ${ }^{26}$. Phaser was supplied with the non-substrate bound structure as a search model (PDB ID 1T0T). Model building and refinement and was done using $\operatorname{Coot}^{26}$ and Phenix. ${ }^{27}$ Electron density maps of the Phaser solution showed the presence of a ligand adjacent to His172 ( $\mathrm{Sa}$ sequence numbering, Fig. S3); Mn-coproheme (designated as 76R in the PDB file) was modeled into this electron density. Iterative rounds of model building with Coot and refinement with Phenix ${ }^{24}$ yielded the final model (PDB ID 5T2K) with $R_{\text {free }}=17.6 \%$ and $R_{\text {work }}=15.4 \%$. The following residues are not included in the final model due to weak electron density: residues 115-123, 114-117, 112-117, 114-119 and 115-123 (all Gs numbering) in subunits A, B C, D and E, respectively. Molecular graphics were created with PyMOL (www.pymol.org).

\section{Determining protein-heme dissociation constants}

Values of $K_{\mathrm{D}}$ for equilibrium binding of decarboxylases/hemes were determined by fluorescence quenching (Cary). Tryptophan fluorescence (5 $\mu \mathrm{M}$ subunit) was excited at 295 $\mathrm{nm}$ and emission monitored at $340 \mathrm{~nm}$. Quenched emission at $340 \mathrm{~nm}$ was plotted versus the concentration of added heme ligand. Plots were fitted with the Langmuir-Hill equation to determine the $K_{\mathrm{D}}$. 


$$
\theta=\frac{[L]^{n}}{K D+[L]^{n}}
$$

$\theta$ is the fraction of ligand-binding sites occupied by the ligand, [L] is the ligand concentration, and $\mathrm{n}$ is the Hill coefficient describing cooperativity.

\section{Reactions of decarboxylase-coproheme complexes monitored following titrimetric addition of oxidants}

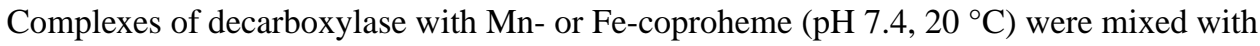
aliquots of $\mathrm{H}_{2} \mathrm{O}_{2}$ or peracetic acid from 1-50 mM stocks. The progress of reactions was monitored by UV/vis spectroscopy (Cary50, samples $10 \mu \mathrm{L}$ in heme species). Reaction products were analyzed by high performance liquid chromatography (HPLC) and HPLC coupled to electrospray ionization mass spectrometry (HPLC-ESI-MS) (samples $40 \mu \mathrm{M}$ in the heme species). MS was used to verify the identities of all reactants and products via their exact masses. Fe-bound coproheme, harderoheme (isomers III or IV), and heme $b$, or Mnbound coproheme/heme $b$ were separated and quantified via their integrated HPLC peak intensities referenced to standard curves:

HPLC: $20 \mu \mathrm{L}$ samples were injected onto a Hypersil Gold PFP $5 \mu \mathrm{m}$ column $(150 \mathrm{~mm} \times 4.6$ $\mathrm{mm}$, Thermo Fisher) attached to an Agillent 1100 series instrument. Solvent $\mathrm{A}$ was $\mathrm{H}_{2} \mathrm{O}$ with $0.1 \%$ trifluoroacetic acid (TFA) and Solvent B was acetonitrile (ACN) with 0.1\% TFA.

Samples were run at a flow rate of $2 \mathrm{~mL} / \mathrm{min}$ starting with isocratic $70 \% \mathrm{~A}: 30 \%$ B for 3 min, followed by a linear gradient transitioning from $70 \% \mathrm{~A}$ to $5 \% \mathrm{~A}$ over $12 \mathrm{~min}$. This was followed by isocratic 5\% A for $5 \mathrm{~min}$ and a final isocratic run of $30 \% \mathrm{~A}$ for $3 \mathrm{~min}$. UV/vis detection was at $411 \mathrm{~nm}$. Standard curves ranging from $0-500 \mathrm{pmol}$ of the tetrapyrroles versus peak areas were constructed. HPLC peak areas were determined in triplicate and error bars are reported as \pm 1 standard deviation.

HPLC-ESI-MS: The chromatography conditions described above were used with an Agilent PLRP-S PSDVB column (PL1312-1300) and 1290 HPLC system. Mass spectra were obtained on an Agilent 6538 quadrupole time of flight (QTOF) instrument with ESI source (drying gas $8.0 \mathrm{~L} / \mathrm{min}$, drying gas heat at $350^{\circ} \mathrm{C}$, nebulizer 55 psi, capillary voltage $3500 \mathrm{~V}$, capillary exit $100 \mathrm{~V}$ ). Spectra were collected in negative mode from 50 to $1700 \mathrm{~m} / \mathrm{z}$ at a rate of $2 \mathrm{~Hz}$.

\section{Steady state kinetics of catalase reactions}

The conversion of $\mathrm{H}_{2} \mathrm{O}_{2}$ to $\mathrm{O}_{2}$ and water by various decarboxylase-metalloporphyrin complexes was monitored continuously over time via polarography using a Clark $\mathrm{O}_{2}$ electrode (YSI). The electrode was equilibrated to $20^{\circ} \mathrm{C}$ for $1 \mathrm{~h}$ using a circulating water bath and calibrated to the concentration of $\mathrm{O}_{2}$ in air-saturated distilled/deionized water. Reactions were carried out in $2 \mathrm{~mL}$ volumes $(50 \mathrm{mM}$ potassium phosphate buffer, $\mathrm{pH} 7.4$ ) with $4 \mu \mathrm{M}$ of enzyme-porphyrin complex and initiated by addition of $10-100 \mathrm{mM} \mathrm{H}_{2} \mathrm{O}_{2}$ stocks via airtight syringe $(5-20 \mu \mathrm{L})$. Linear initial rates $\left(\mathrm{v}_{\mathrm{i}}\right)$ were fit by least-squares 
regression to the first 5-10\% of the progress of reaction curves (Kaleidagraph). Plots of $v_{i}$ versus $\mathrm{H}_{2} \mathrm{O}_{2}$ concentration were fit to the Michaelis Menton equation:

$$
\frac{v}{E}=\frac{k_{c a t}[H 2 O 2]}{K_{m}+[H 2 O 2]}
$$

Here, $\mathrm{E}$ is the concentration of enzyme-metalloporphyrin complex. Unreacted $\mathrm{H}_{2} \mathrm{O}_{2}$ was quantified at the end of reactions using horseradish peroxidase (HRP) and a colorimetric substrate (2,2'-Azinobis [3-ethylbenzothiazoline-6-sulfonic acid]-diammonium salt, ABTS). $0.5 \mathrm{U} / \mathrm{mL} \mathrm{HRP}$ and $500 \mu \mathrm{M} \mathrm{ABTS}$ (final concentrations) were added to the samples and incubated $\left(25^{\circ} \mathrm{C}\right)$ for $1 \mathrm{hr}$. The absorbance at $738 \mathrm{~nm}$ was recorded and compared with a standard curve generated over 5-100 $\mu \mathrm{M} \mathrm{H}_{2} \mathrm{O}_{2}$ ].

\section{Resonance Raman (rR) spectroscopy}

Ferric samples for $\mathrm{rR}$ experiments were prepared at 25 to $60 \mu \mathrm{M}$ coproheme-decarboxylase complex in $100 \mathrm{mM}$ sodium phosphate at $\mathrm{pH} 7.5$ Using Schlenk techniques, ferrous complexes were prepared anaerobically at $20^{\circ} \mathrm{C}$ from ferric enzymes by reduction with an excess of buffered sodium dithionite. The $\mathrm{CO}$ complexes were prepared by flushing the ferrous enzymes with natural abundance $\mathrm{CO}$ or ${ }^{13} \mathrm{CO}\left(99 \%{ }^{13} \mathrm{C}\right)$.

The rR spectra were recorded using the $135^{\circ}$ backscattering geometry and $\mathrm{f} 1$ collection using a previously described spectrometer. ${ }^{21}$ Either the 406.7-nm or the 413.1-nm emission line from a $\mathrm{Kr}+$ laser was used for Raman excitation, and the laser beam was focused to a line on a spinning $5 \mathrm{~mm}$ NMR tube. External spectral calibration standards for the $\mathrm{rR}$ spectra were toluene, acetone, methylene bromide, and $\mathrm{d}^{6}$-dimethylsulfoxide. Laser power for ferric samples ranged from 4 to $12 \mathrm{~mW}$; ferrous $\mathrm{CO}$ complexes required laser irradiation powers of 1 to $3 \mathrm{~mW}$ to prevent $\mathrm{CO}$ photolysis. To check the integrity of the rR samples, their UV-visible spectra were checked before and after irradiation in the laser beam. Normal mode assignments were made by analogy to other heme proteins. Peak fitting analyses of the $\mathrm{rR}$ spectra were based on the minimum number of peaks required to achieve statistically valid fits of the spectra. Band shapes were assumed to be Gaussian and were well modeled by Gaussian line-shape functions.

\section{RESULTS}

\section{Co-crystals of the decarboxylase with $\mathrm{Mn}$-coproheme diffracted to $1.8 \AA$ A resolution}

Our ongoing biochemical characterization of the coproheme decarboxylase and its genetic knock out has focused on $S$. aureus due to the importance of pathogenic strains of that species. ${ }^{21,28}$ Robotic screening of thousands of crystallization conditions failed to generate diffraction-quality crystals of the enzyme from $\mathrm{Sa}$, either alone or in complex with metalloporphyrins. However, the substrate-free structure of a coproheme decarboxylase from another member of its phylum, Geobacillus stearothermophilus, was available through a structural genomics consortium (PDB ID: 1T0T). ${ }^{23}$ The $G s$ and $S a$ proteins have 59\% sequence identity (Fig. S3). UV-vis and rR spectra (Fig. S4-S5) and reactivity (Fig. S5) for the two are similar, though the Gs enzyme appears to require more $\mathrm{H}_{2} \mathrm{O}_{2}$ to convert bound 
coproheme or harderoheme to heme $b$, and the heme $b$ complex with the protein is less stable (reflected in its higher $K_{\mathrm{D}}$, Table S2). The lower protein/heme $b$ affinity for the $G s$ decarboxylase may be responsible for the increased susceptibility of the heme $b$ to degradation by $\mathrm{H}_{2} \mathrm{O}_{2}$, apparent in the $\mathrm{H}_{2} \mathrm{O}_{2}$ titration data shown in Fig. S5. Given the overall similarity between the $S a$ and $G$ s proteins, we therefore attempted to generate crystals with $\mathrm{Fe}(\mathrm{III})$ coproheme using the $G s$ decarboxylase, which was likewise unsuccessful. The enzyme complex with the substrate analog $\mathrm{Mn}(\mathrm{III})$ coproheme, however, yielded large crystals that diffracted to 1.8 A resolution (Table S3). In solution, neither the Gs nor the $S a$ $\mathrm{Mn}$ (III)coproheme-decarboxylase complex reacted with $\mathrm{H}_{2} \mathrm{O}_{2}$ (up to 50 eq). However, the $\mathrm{Mn}(\mathrm{III})$ complexes reacted with peracetic acid (PAA), yielding the expected Mn-substituted harderoheme intermediate and heme $b$ products (Fig. S6). ${ }^{22}$ These results suggest that the $\mathrm{Mn}$ (III)coproheme binds in the catalytic orientation but is incapable of activating $\mathrm{H}_{2} \mathrm{O}_{2}$ and therefore is stable as a solid state complex in the presence of $\mathrm{O}_{2}$ and ionizing X-ray radiation, conditions under which $\mathrm{H}_{2} \mathrm{O}_{2}$ may be spontaneously produced.

\section{Structural changes associated with substrate binding to coproheme decarboxylase are confined to the $\mathrm{C}$-terminus}

Like other members of its family (Pfam 06778, which includes both chlorite dismutase [Cld] and coproheme decarboxylase enzymes), ${ }^{29}$ the crystal structure of the $G s$ coproheme decarboxylase is a homopentamer where each subunit consists of two ferrodoxin-like $\alpha / \beta$ domains connected by a pseudo-twofold axis (Fig. 1A). The same domain is shared by both non-canonical IsdG-type heme oxygenases and heme-binding DyP-type peroxidases, as previously noted. ${ }^{28}$ The superimposed structures of the ligand-free (PDB ID 1T0T) ${ }^{23}$ and bound $(5 \mathrm{~T} 2 \mathrm{~K})$ forms of subunit A are shown in Fig. 1B $(\mathrm{Ca}$ RMSD $=0.47 \mathrm{~A})$. The peptide backbone and side chains mostly overlay, with the structural changes accompanying ligand binding confined to the $\mathrm{C}$-terminal region housing the $\mathrm{Mn}$-coproheme. In particular, residues 111-121 form part of a loop on the solvent-exposed exterior of the ligand-free homopentamer, where they might constitute the site of substrate entry/product egress. ( $\mathrm{Sa}$ residue numbering is used except where noted.) The most dramatic rearrangements in the ligand-bound structure occur here (Fig. 1C). Though several of its side chains could not be modeled due to weak electron density in this region for the individual coproheme-bound subunits, the loop as a whole folds inwards toward the coproheme in the ligand-bound structure. This rearrangement brings the side chain of Asn112, which occupies a position inside the substrate-binding pocket, toward the protein exterior in the ligand-bound structure. Tyr113 and Arg131, by contrast, form new contacts with propionates 4 and 6, respectively, which could be significant for the oxidative decarboxylation mechanism (see below).

\section{Coproheme binding site structure: Implications for mechanism}

The electron density map for Mn-coproheme bound to the active site (Fig. 2A) illustrates the unambiguous assignment of the atomic positions of the porphyrin and all of its side chains in the crystal structure. The porphyrin ring is slightly ruffled, occupying roughly the same position as the molecule of solvent in the ligand-free structure or the heme $b$ which serves as a cofactor in Clds. However, the coproheme is rotated approximately $90^{\circ}$ about the pseudo$\mathrm{C}_{4}$ axis relative to the heme $b$ in either Cld (Fig. S7) or energy-minimized predictions of the structure of the decarboxylase-coproheme complex. ${ }^{31}$ This orientation positions the two 
unreactive propionates ( 6 and 7, Scheme 1) pointing outward from the protein toward the solvent, where they occupy positions on the distal side of the heme plane (Fig. 2B). The two reactive propionates ( 2 and 4 ), by contrast, are rotated to the proximal side of the porphyrin plane and well beyond the reach of the open, distal coordination site.

On the other side of the plane (proximal pocket), histidine 172 coordinates the Mn of the coproheme (2.3 A) via the imidazole- $\mathrm{N}_{\varepsilon}$ atom (Fig. $2 \mathrm{~B}$ ). The imidazole- $\mathrm{N}_{\delta}$ is $\mathrm{H}$-bonded to a water molecule, which is itself H-bonded to Ser222, Asp219, and the Met216 main chain carbonyl. Most $\mathrm{H}_{2} \mathrm{O}_{2}$-activating heme enzymes as well as Clds have an aspartic or glutamic acid as the hydrogen bonding donor in the analogous position, ${ }^{32-34}$ leading to some degree of negative charge in the proximal ligand. The negatively charged histidine supplies an electronic push that favors heterolytic cleavage of the O-O bond in the heme-Fe(III)-OOH that forms in trans. Water is a comparatively weak $\mathrm{H}$-bonding partner; consistent with previously reported $\mathrm{rR}$ spectra, ${ }^{21}$ His 172 is electronically neutral, leading to a more globinlike metal-His interaction.

The distal pocket (Fig. 2C) is likewise distinct from other $\mathrm{H}_{2} \mathrm{O}_{2}$-reactive heme proteins. Canonical peroxidases share a distal histidine with a relatively low $\mathrm{p} K$ a due to a nearby arginine. ${ }^{34}$ In its deprotonated form, the distal His acts as a base toward $\mathrm{H}_{2} \mathrm{O}_{2}(\mathrm{p} K \mathrm{a}=11)$. Heterolytic bond cleavage in the resulting heme-Fe(III)-OOH complex is catalyzed by proton donation from the His-Arg pair, yielding Compound $\mathrm{I}$ and $\mathrm{H}_{2} \mathrm{O}$. By contrast, the distal environment in the coproheme decarboxylase is relatively hydrophobic. Ile187 hovers over the center of the porphyrin plane. Gln185 resides at its side and in the same sequence/ structural position occupied by the distal arginine from Clds (Fig. S8). This residue, which distinguishes the decarboxylase- and dismutase-encoding hem $Q$ and cld genes, is important for the heme-dependent chlorite $\left(\mathrm{ClO}_{2}^{-}\right)$decomposition mediated by Clds to yield $\mathrm{Cl}^{-}$and $\mathrm{O}_{2} \cdot{ }^{35}$

At the edge of the distal pocket nearest the solvent interface, the Arg131 side chain sits at the center of a H-bonding network involving propionate $6, \mathrm{Gln} 185$, and a water molecule (Fig 2C). This water occupies a position close to where the terminal oxygen of a coproheme$\mathrm{Fe}(\mathrm{III})-\mathrm{OOH}$ intermediate could reside. Though the solution $\mathrm{p} K \mathrm{a}$ of the Arg side chain is high (12.5) and the propionate is low (3.2-3.5), the two together could in principle act as a base toward $\mathrm{H}_{2} \mathrm{O}_{2}$, an acid toward coproheme-Fe(III)-OOH, or both. An arginine side chain with a similar H-bond to a propionate has been proposed to act as a distal base in lieu of HisArg in dye decoloring peroxidases. ${ }^{36}$ Prior work showed that the second order reaction between the decarboxylase-coproheme complex and $\mathrm{H}_{2} \mathrm{O}_{2}$, which leads to the ferric heme $b$ complex, accelerates with $\mathrm{pH}(\sim 3$-fold, $\mathrm{p} K \mathrm{a}=7.4)$ and is solvent-isotope dependent (average $\left.k\left(\mathrm{H}_{2} \mathrm{O}\right): k\left(\mathrm{D}_{2} \mathrm{O}\right)=2.2\right) .{ }^{22}$ Both results suggest the involvement of proton movement in the rate limiting step of the $\mathrm{H}_{2} \mathrm{O}_{2}$ reaction. However, $\mathrm{pH}$ has a much larger influence over the analogous, acid-base-catalyzed steps in heme peroxidases. ${ }^{34,37}$ The roles of these residues and of $\mathrm{pH}$ therefore remain to be determined.

Reactive propionates 2 and 4 are each converted (net $2 \mathrm{e}^{-}+1 \mathrm{H}^{+}$lost per propionate) to a vinyl group and $\mathrm{CO}_{2}$ by a $\mathrm{H}_{2} \mathrm{O}_{2}$-mediated oxidation reaction (Scheme 1). Key residues surrounding each are shown in Figs. 2D and E. Propionate 2, which reacts first, ${ }^{21,22}$ forms 
H-bonds to the side chain hydroxyls of Ser223 (2.2 A) and Tyr145 (2.8 A). The former is part of a H-bonding network leading to the proximal His172. The latter is just 3.1 A away from the $\mathrm{C}_{\beta}$ of the propionate (Scheme 1).

This was the observed site of net hydrogen atom removal catalyzed by coproporphyrinogen oxidase, ${ }^{38}$ an enzyme that carries out analogous oxidative decarboxylations on the metalfree, reduced analog of coproheme III. Removal of a hydrogen atom at this position leaves a carbon radical conjugated to, and consequently stabilized by, the tetrapyrrole. Additionally, propionate 2 is $\mathrm{H}$-bonded to a water molecule which is in turn H-bonded to Arg218. Propionate 4 is directly H-bonded/salt-bridged to Lys149 (2.7 A), and indirectly to Trp156 and Tyr 113 by a network of $\mathrm{H}$-bonds including a bridging water molecule. Another H-bond network leads to Trp198 via the $\mathrm{O}_{\varepsilon 1}$ atom of Glu109 and a second water molecule. The $\mathrm{N}_{\varepsilon}$ of Trp198 has the closest through-space approach to the $\mathrm{C}_{\beta}$ of propionate 4 (3.9 A). The occurrence of multiple residues with possible redox (Tyr, Trp) and proton-translocating activities suggests one or more may be involved in catalyzing the two oxidative decarboxylations.

The solution state $S a$ and $G s$ decarboxylase heme environments are similar to one another and distinct from chlorite dismutases. Resonance Raman spectra were measured for the $\mathrm{Sa}$ and $G s$ decarboxylases in complex with ferric coproheme and heme $b$ (Fig. 3A). Comparison of the low frequency spectra of the coproheme complexes demonstrated similarities in their propionate bending $\left(\delta\left(\mathrm{C}_{\beta} \mathrm{C}_{c} \mathrm{C}_{\mathrm{d}}\right)\right.$, in this nomenclature $\mathrm{C}_{\mathrm{c}}$ and $\mathrm{C}_{\mathrm{d}}$ correspond to carbons labeled $\mathrm{C}_{\beta}$ and $\mathrm{C}_{\alpha}$ in Scheme 1 frequencies ( $S a$ : 374 and $393 \mathrm{~cm}^{-1}$; Gs: 374 and $395 \mathrm{~cm}^{-1}$ ). Reaction of both coproheme-decarboxylase complexes with $\mathrm{H}_{2} \mathrm{O}_{2}$ (Fig. S3) yielded comparable rR spectral changes, ${ }^{21}$ including the appearance of bands corresponding to vinyl stretching and bending modes with very similar frequencies (1627 and $415-418 \mathrm{~cm}^{-1}$, respectively). The $374-\mathrm{cm}^{-1}$ propionate bending frequency is unaffected by decarboxylation while the second propionate bending frequency decreases by $4 \mathrm{~cm}^{-1}$ in both decarboxylases. The similarities between the solution spectra and reactivities of the $G s$ and $S a$ enzyme-substrate complexes suggest it is reasonable to expect that their structures, especially the positioning of their reactive coproheme 2-and 4-propionate groups, are comparable.

Prior simulations of coproheme binding to the decarboxylase had the non-reactive propionates 6 and 7 in the same positions as the propionates of the heme $b$ in the Cld structures, in contrast with the solid state structure shown here. ${ }^{31}$ Unique peripheral substituent environments of ferric heme $b$ in decarboxylases and Clds are supported by their propionate and vinyl $\left(\delta\left(\mathrm{C}_{\beta} \mathrm{C}_{\mathrm{a}} \mathrm{C}_{\mathrm{b}}\right)\right)$ bending mode frequencies. The decarboxylase complexes exhibit $\delta\left(\mathrm{C}_{\beta} \mathrm{C}_{\mathrm{c}} \mathrm{C}_{\mathrm{d}}\right)$ and $\delta\left(\mathrm{C}_{\beta} \mathrm{C}_{\mathrm{a}} \mathrm{C}_{\mathrm{b}}\right)$ frequencies $8-11 \mathrm{~cm}^{-1}$ and $4-8 \mathrm{~cm}^{-1}$ lower, respectively, relative to those modes in WT $D a C l d$ and $D a C l d ~ A r g 183 G l n$ mutant (Fig. 3A). ${ }^{35}$ The latter substitution exchanges the Cld-associated distal Arg with the distal Gln of the $\mathrm{Sa}$ decarboxylase, rendering their distal environments more similar. To further examine the solution state environment of the non-reactive propionates, the $\mathrm{rR}$ spectrum for the ferrous $S a$ decarboxylase-heme $b$ complex with $\mathrm{CO}$ was measured and compared with counterpart spectra from WT DaCld and the DaCld(R183Q) (Fig. 3B). Comparison of the decarboxylase- $\mathrm{CO}$ and Cld-CO spectra clearly shows that the bands associated with 
propionate and vinyl bending, as well as the porphyrin ring, occur at different frequencies and with different band widths. The bending modes for propionates 6 and 7 of heme $b$ :decarboxylase-CO are observed at 377 and $395 \mathrm{~cm}^{-1}$, in contrast to one broad band at 372 $\mathrm{cm}^{-1}$ in the DaCld-CO spectrum. The frequency of the vinyl bending mode for heme $b$ :decarboxylase-CO is $10 \mathrm{~cm}^{-1}$ lower than that of WT $D a C l d ~\left(416\right.$ versus $426 \mathrm{~cm}^{-1}$ ). The DaCld R183Q mutation has little effect on these propionate frequencies, suggesting that the observed differences in the spectra are not due to differences in their distal environments. In addition to these differences in vinyl/propionate-associated frequencies, the $\nu_{8}$ core size marker band (M-N stretch) of the heme $b$ :decarboxylase-CO occurs at $348 \mathrm{~cm}^{-1}$, and $8-9$ $\mathrm{cm}^{-1}$ higher in frequency in the $\mathrm{DaCld}$ spectrum. Finally, a large band at $341 \mathrm{~cm}^{-1}$ that is tentatively assigned to the pyrrole tilting mode $\left(\gamma_{6}\right)$ in $\mathrm{DaCld}$ is absent from the decarboxylase spectrum. These differences collectively reveal distinct peripheral and core heme conformations for the decarboxylases and Clds.

Solution-state spectroscopy indicates retention of the weak Fe-His bond but diminishing distal interactions as the propionates are oxidized. The ferrous heme-CO complex is a sensitive probe of heme coordination and the electrostatic character of its binding site inside proteins. ${ }^{39-42}$ The $\mathrm{CO}$ complexes of the ferrous coproheme-, harderoheme-, and heme $b$ bound decarboxylase ( $\mathrm{Sa}$ ) were generated and their spectra analyzed for inclusion on a $\nu_{\mathrm{Fe}-\mathrm{C}} / \nu_{\mathrm{C}-\mathrm{O}}$ correlation plot (Fig. 4). Three isotope-sensitive (i.e. ${ }^{12} \mathrm{CO}$ versus ${ }^{13} \mathrm{CO}$ ) bands were detected for each of the aforementioned hemes. Based on their frequencies and isotope shifts, they were assigned to the $\mathrm{Fe}-\mathrm{C}$ and $\mathrm{C}-\mathrm{O}$ stretching $\left(\nu_{\mathrm{Fe}-\mathrm{C}}\right.$ and $\left.\nu_{\mathrm{C}-\mathrm{O}}\right)$ and $\mathrm{FeCO}$ bending $\left(\delta_{\mathrm{FeCO}}\right)$ modes for CO-bound forms: coproheme, 513, 1941, and $582 \mathrm{~cm}^{-1}$; harderoheme, 502, 1955, and $579 \mathrm{~cm}^{-1}$; heme $b, 498,1958$, and $577 \mathrm{~cm}^{-1}$, respectively (Fig. 4A). The same isotopically sensitive bands were observed for the heme $b$-CO, whether generated by binding ferric heme $b$ to the enzyme or by the enzymatic activity of the decarboxylase.

All of the CO complexes generated here fell on the inverse correlation line associated with charge-neutral proximal histidine ligands (Fig. 4B), consistent with the proximal pocket structure (Fig. 2B) and with retention of the proximal histidine as the substrate converts to product. However, the location along the histidine correlation line for the three decarboxylase complexes varied, consistent with a changing distal environment. Stronger interactions of the $\mathrm{CO}$ ligand with positively charged or H-bond donating residues on the distal side of the heme lead to greater $\pi$ back bonding and, therefore, to points higher on the imidazole line. The decarboxylase complex with coproheme is highest on the line, in a position consistent with moderate $\mathrm{H}$-bond donation to or electrostatic interaction with the bound $\mathrm{CO}$ and the distal pocket. The harderoheme complex is much lower on the correlation line and close to the position of heme $b$, which is lowest of all. The loss of $\mathrm{Fe}-\mathrm{C} \pi$ bonding character and increase in the $\mathrm{C}-\mathrm{O} \pi$ bonding character in the three $\mathrm{CO}$ complexes is consistent with the progressive loss of distal interaction as the substrate is oxidized.

The positions of these complexes on the line can be further interpreted in terms of distal structure using available data from Clds. Two conformers, described as closed and open forms, have been reported for the $\mathrm{pH} 6.5$ and 9 crystal structures of $\mathrm{DaCld}$ as well as in rR spectra of DaCld-CO. ${ }^{45,46}$ These have the distal Arg183 oriented toward and away from the 
open coordination position above the heme plane, respectively. The

coproheme:decarboxylase-CO is comparable to the closed form of $\mathrm{DaCld}(\mathrm{Arg} 183 \mathrm{Gln})-\mathrm{CO}$, suggesting similar distal environments. The closed form of WT DaCld-CO, with its distal Arg, is higher up on the correlation line; as one would predict, the distal Arg interacts with the bound $\mathrm{CO}$ in a stronger manner than the distal Gln in either coproheme: decarboxylase$\mathrm{CO}$ or $\mathrm{DaCld}(\operatorname{Arg} 183 \mathrm{Gln})-\mathrm{CO}$. The heme $b$ :decarboxylase-CO falls at a position similar to the open form of DaCld-CO and the CO complex of the Cld from Candidatus Nitrospira defluvii. ${ }^{47}$ The degree of distal pocket interaction with the bound $\mathrm{CO}$ in these three complexes is similar and small.

\section{Coproheme-bound $\mathrm{CO}$ interacts with the conserved distal GIn}

The crystal structure suggests that Gln185 and/or Arg131 could make contact with the terminal oxygen of a ferric coproheme-OOH complex. To examine this hypothesis, $\mathrm{rR}$ spectra for the ferrous coproheme-CO complexes were used to assess the distal environment sampled by a bound diatomic ligand inside the Gln185Ala and Arg131Ala variant decarboxylases. The $\nu_{\mathrm{Fe}-\mathrm{C}}$ and $\nu_{\mathrm{C}-\mathrm{O}}$ frequencies for the Gln185Ala-CO complex (498 and $1953 \mathrm{~cm}^{-1}$, respectively (Fig. S9) dramatically shift the Gln185Ala-CO point down the correlation line away from the WT coproheme complex and to a position close to the heme $b$-decarboxylase (Fig. 4B.). This indicates loss of distal interaction when Gln185 is absent. The Arg131Ala-CO complex falls between WT and Gln185Ala on the $\nu_{\mathrm{Fe}-\mathrm{C}} / \nu_{\mathrm{C}-\mathrm{O}}$ correlation plot (Fig. 4B and S8) indicating that this mutation has a smaller effect on the distal pocket interaction than Gln185Ala. Its distal environment is comparable to those observed for mutants in which H-bonds/salt bridges to a propionate group have been disrupted (see below). This suggests that Arg131 plays a role at the periphery of the coproheme instead of in the distal pocket. Loss of the Arg charge could result in either a change in coproheme conformation because of loss of the interaction with propionate 6 or in an increase in solvent accessibility to the pocket. Either could be responsible for the characteristics of Arg131Ala-CO and its decreased activity with $\mathrm{H}_{2} \mathrm{O}_{2}$ described below. Consistent with these observations, the Gln185Ala but not the Arg131Ala exhibits impaired reactivity (described below).

\section{Disruption of $\mathbf{H}$-bonding to propionates 2 and $\mathbf{4}$ alters heme conformation}

The presence of H-bonds or salt bridges to propionates 2 (Tyr145, Arg218) and 4 (Lys149) are predicted by the structure (Fig. 2). To test whether these apparent interactions modulate the electronic structure of the coproheme, the site-specific Tyr145Ser, Lys149Ala, and Arg218Ala mutants were generated. The rR spectra of these coproheme: mutant-CO complexes are compared in Fig. 4B and $\mathrm{S} 8$ and their $\nu_{\mathrm{Fe}-\mathrm{C}}$ and $\nu_{\mathrm{C}-\mathrm{O}}$ frequencies given in Table S4. As judged by their position on the $\nu_{\mathrm{Fe}-\mathrm{C}} / \nu_{\mathrm{C}-\mathrm{O}}$ correlation plot (Fig. $4 \mathrm{~B}$ ) the mutant:coproheme-CO complexes, like WT coproheme-CO, retain the neutral His as the proximal ligand. The $\mathrm{CO}$ interactions with their distal environments, however, have been diminished. If the only role of the H-bonds/salt bridges to the reactive propionates is to position them for decarboxylation, loss of these interactions would not be expected to change exogenous ligand interactions with the distal pocket. This result therefore argues that the roles of the H-bond donors to propionates 2 and 4 are more nuanced than simply positioning their carboxylate groups and the changes in their reactivity could be due, in part, 
to changes in the distal pocket interactions and/or distortions of the coproheme plane that direct the reactivity of the high-valent intermediate toward oxidative decarboxylation of propionate 2 or 4 .

Three bands have been tentatively assigned to propionate bending modes in the CO complexes of WT, Tyr145Ser, Arg218Ala and Lys149Ala coproheme:decarboxylases (Fig. S8B and Table S4). The Try145Ser mutant has a propionate bending band at $361 \mathrm{~cm}^{-1}$ that is $6 \mathrm{~cm}^{-1}$ lower than the comparable $\delta\left(\mathrm{C}_{\beta} \mathrm{C}_{\mathrm{c}} \mathrm{C}_{\mathrm{d}}\right)$ band in the WT CO complex; the other two $\delta\left(\mathrm{C}_{\beta} \mathrm{C}_{\mathrm{c}} \mathrm{C}_{\mathrm{d}}\right)$ frequencies are unaffected indicating that the band at $367 \mathrm{~cm}^{-1}$ in the WT CO spectrum is due to propionate-2. Loss of the Try $145 \mathrm{H}$-bond to propionate 2 results in a significant alteration in its environment. In contrast, all three bands assigned to the propionate bending modes in Arg218Ala and Lys149Ala CO complexes exhibit decreases of $3 \mathrm{~cm}^{-1}$ in their frequencies of relative to WT. This indicates that disruption of the H-bond network between propionate 2 and Arg218 or the salt bridge between Lys149 and propionate 4 lead to more global changes in coproheme environment than the very localized effect of Tyr 145 mutation. Interestingly, the $v_{8}$ band, a core size marker band that reports Fe- $\mathrm{N}_{\text {pyrrole }}$ stretching, exhibits a decrease in frequency for all three mutants. This is consistent with increases in the porphyrin core size upon mutation of the amino acids that interact with the reactive propionates 2 and 4 . These features suggest that the interaction of these residues with the coproheme are important in determining the degree to which the heme conformation deviates from planarity. Thus, stepwise changes in the heme planarity may contribute to the structural basis for regioselectivity in oxidizing propionates 2 and 4 .

Tyr145 is essential for the decarboxylation of coproheme and harderoheme III; Lys149 contributes to decarboxylation of harderoheme III. Based on their proximity to the substrate and their catalytic roles in other enzymes, we hypothesized that several residues in Fig. 2 may have essential roles in catalysis. We made a series of mutations in the Sa enzyme at a total of eight key positions, including those described above (Table S2). All of the mutants bound coproheme with $>80 \%$ occupancy, with $K_{D}$ values similar to WT and varying by less than an order of magnitude (Table S2, Fig. S10-11). The catalytic competence of each mutant-coproheme complex was examined to determine which residues were essential for turnover, specifically whether each generated the expected intermediate (harderoheme III) and product (heme $b$ ) and how much oxidant was required.

The WT enzyme required 5 eq of $\mathrm{H}_{2} \mathrm{O}_{2}$ to turn over $90 \%$ of the initially bound coproheme. Harderoheme III was the observed intermediate, maximizing after delivery of 2 eq $\mathrm{H}_{2} \mathrm{O}_{2}$ (Fig. S5) and fully converting to heme $b$ with a total of 10-12 eq $\mathrm{H}_{2} \mathrm{O}_{2}$. Addition of further oxidant has been observed to bring about the complete degradation of the heme $b$ chromophore. $^{21}$

The most dramatic deviations from WT behavior were obtained for the Tyr145Ser and Lys149Ala mutants (Fig. 5). Tyr145Ser, in which the H-bond to propionate 2 is eliminated, required $\sim 3,000$ eq of $\mathrm{H}_{2} \mathrm{O}_{2}$ to turn over $\geq 95 \%$ of the coproheme substrate (Table S2). Neither harderoheme III nor heme $b$ appeared as intermediates or products. Instead, the coproheme degraded without detectable products. The Tyr145Ser mutant readily bound harderoheme so its catalytic competence towards this stable intermediate was investigated. 
Harderoheme-Tyr145Ser mutant did not form observable heme $b$ upon reaction with $\mathrm{H}_{2} \mathrm{O}_{2}$ (Fig. S12). The Lys149Ala mutant, in which the salt bridge to propionate 4 is removed, required $\sim 300$ eq of $\mathrm{H}_{2} \mathrm{O}_{2}$ to turn over $\geq 95 \%$ of the substrate. However, the major product was harderoheme III, with relatively little turnover of this species to heme $b$. This suggests that Lys149 is essential specifically for the conversion of harderoheme to heme $b$, while Tyr145 appears to play a role in both decarboxylation reactions.

Substitutions of other potentially significant residues surrounding propionate 2 (Arg218Ala) or 4 (Tyr113Ser, Trp157Phe, Trp198Phe), or in the distal pocket (Gln185Ala, Arg131Ala) had far smaller effects, suggesting that none of these on its own is essential for catalysis. Instead, the Gln185Ala and Arg131Ala mutants brought about small increases in the amount of $\mathrm{H}_{2} \mathrm{O}_{2}$ required to effect substrate conversion (60 and 24 eq, respectively). The Gln185Ala mutant additionally saw exhibited a marked decrease in the amount of harderoheme III accrued, suggesting this mutation had a proportionally greater impact on the first decarboxylation than the second. Arg218Ala, Trp157Phe, and Trp198Phe all behaved very similarly to WT, while the heme $b$ product of Tyr113Ser was slightly less stable toward $\mathrm{H}_{2} \mathrm{O}_{2}$, possibly due to weaker heme $b$ binding (Fig. S13).

The excess $\mathrm{H}_{2} \mathrm{O}_{2}$ required for coproheme turnover can be largely accounted for by catalase activity. The $S a$ decarboxylase containing heme $b$ was previously shown to have catalase activity:

$$
\begin{gathered}
\mathrm{Fe}(\mathrm{III}) \text { heme }+\mathrm{H}_{2} \mathrm{O}_{2} \rightarrow \mathrm{Fe}(\mathrm{IV})=\mathrm{O}(\text { por } \bullet+) \\
\mathrm{Fe}(\mathrm{IV})=\mathrm{O}(\text { por } \bullet+)+\mathrm{H}_{2} \mathrm{O}_{2} \rightarrow \mathrm{O}_{2}+\mathrm{H}_{2} \mathrm{O}
\end{gathered}
$$

This reaction ( $\sim 50$ turnovers) occurs concomitantly with heme $b$ degradation. ${ }^{28}$ It is possible that some of the excess $\mathrm{H}_{2} \mathrm{O}_{2}$ required for coproheme conversion to heme $b$ might be expended in the catalase reaction. Following addition of 12 eq of $\mathrm{H}_{2} \mathrm{O}_{2}(120 \mu \mathrm{M})$ to the decarboxylase-coproheme complex $(10 \mu \mathrm{M})$, one eq of $\mathrm{O}_{2}(10 \mu \mathrm{M})$ (measured by $\mathrm{O}_{2}$ polarography) (Fig. 6A) was generated over the same time frame in which coproheme converted to heme $b$. In light of the mechanism above, 2 eq of $\mathrm{H}_{2} \mathrm{O}_{2}$ (likely not a physiologically relevant amount) can be accounted for via the catalase reaction, in addition to the 2 required for the decarboxylation reactions. The remaining 8 of the initial $12 \mathrm{eq}$, though well within the limits of detection, were not detected by HRP-based colorimetric assays as the end of the reaction. Control reactions in which the ligand-free/apo-protein (5 $\mu \mathrm{M})$ was mixed with 12 eq $\mathrm{H}_{2} \mathrm{O}_{2}(60 \mu \mathrm{M})$ under the same conditions showed that $\sim 8$ eq of $\mathrm{H}_{2} \mathrm{O}_{2}(40 \mu \mathrm{M})$ were consumed in a heme-independent reaction with the apo-protein without concomitant production of $\mathrm{O}_{2}$, while 4 eq $(22 \mu \mathrm{M})$ remained unreacted in solution (Fig. S14).

The large excess of $\mathrm{H}_{2} \mathrm{O}_{2}$ required to turn over the coproheme bound to the Tyr149Ser and Lys145Ala mutants could likewise be primarily accounted for via the catalase reaction (Fig. 
S15). Mutation of either residue increases the values of both $k_{\text {cat }}$ and $k_{\text {cat }} / K_{\mathrm{M}}\left(\mathrm{H}_{2} \mathrm{O}_{2}\right)$ relative to WT (Fig. 6B). This suggests that either mutation stabilizes the heme species, thereby enhancing their efficiency as catalases.

\section{DISCUSSION}

Coproheme decarboxylase catalyzes $\mathrm{H}_{2} \mathrm{O}_{2}$-dependent $\mathrm{C}-\mathrm{C}$ bond cleavage reactions to liberate two molecules $\mathrm{CO}_{2}$ from a pair of propionic acids, converting each to a vinyl (Scheme 1). An analogous reaction is catalyzed by the bacterial cytochrome P450, OleT. ${ }^{48}$ Ferric OleT and $\mathrm{H}_{2} \mathrm{O}_{2}$ react to generate compound $\mathrm{I}$, which in turn abstracts a hydrogen atom directly from the exogenous carboxylic acid substrate. Unique among P450s, this reaction is not followed by rebound between the substrate radical and $\mathrm{Fe}(\mathrm{IV})-\mathrm{OH} .{ }^{19}$ Instead, the reaction is more peroxidase-like, with the unpaired electron from the nearby substrate reducing the iron to $\mathrm{Fe}(\mathrm{III})$, resulting in $\mathrm{CO}_{2}$ and the alkene. A similar mechanism could be proposed for the coproheme decarboxylase, with the ferryl oxygen most likely interacting for steric reasons with the $\mathrm{C}_{\mathrm{a}}-\mathrm{H}$ of either propionate 2 or 4 (Scheme 1). However, the $1.8 \mathrm{~A}$ structure of the enzyme in complex with its substrate analog (Fig. 1-2) suggests two complications with any straightforward application of either the peroxidase or OleT model to the coproheme decarboxylase.

The first is that the apparatus for activating $\mathrm{H}_{2} \mathrm{O}_{2}$ found in most heme peroxidases, including CCP and APX (Fig. S1 and Results), ${ }^{12}$ is completely absent in the coproheme decarboxylase. The coproheme is instead ligated by an uncharged proximal His (Fig 2-4) and its open coordination position is flanked by a distal Gln. Both the Gln and the Arg to which it is connected via H-bonds through-water interact with a coproheme-bound CO. Although mutagenesis showed that neither Gln185 nor Arg131 was essential for catalysis, their interactions with bound $\mathrm{CO}$ suggests they could play activating roles toward $\mathrm{H}_{2} \mathrm{O}_{2}$. Some role for the protein is supported by prior studies of the reaction of the coproheme decarboxylase with peracetic acid: an oxygen atom donor that directly converts ferric hemes to $\mathrm{Fe}(\mathrm{IV})=\mathrm{O}($ por + ) or $\mathrm{Fe}(\mathrm{IV})=\mathrm{O}(\operatorname{Trp} \boldsymbol{+}+)$ without the proton movement or heterolytic bond cleavage associated with $\mathrm{H}_{2} \mathrm{O}_{2} \cdot{ }^{22}$ The ferric coproheme decarboxylase reacts rapidly with peracetic acid to form the expected harderoheme intermediate and heme $b$ product. The second order rate constant for the same reaction with $\mathrm{H}_{2} \mathrm{O}_{2}$ is 10-fold slower and, in contrast with the peracid reaction, dependent on both $\mathrm{pH}$ and solvent isotope $\left(\mathrm{D}_{2} \mathrm{O}\right){ }^{22}$ These observations strongly suggest that the reaction proceeds through a ferryl intermediate and that its formation is facilitated by protein-mediated proton transfers (Scheme 2A).

The second issue concerns the presumptive sites of substrate oxidation - the $\mathrm{C}_{\beta}-\mathrm{H}$ bonds of propionic acids 2 and 4 - which the structure shows are spatially removed from the site of $\mathrm{H}_{2} \mathrm{O}_{2}$ activation at the metal. This separation immediately suggests that, in contrast with OleT, the reaction cannot proceed by direct interaction of a ferryl or other iron/oxygen intermediate with either propionate. A similar steric problem was noted previously in studies of mammalian peroxidases and some cytochrome P450s in which the methyl side chains of heme $b$ are oxidatively modified via a compound I intermediate. In each case, the steric relationships between the ferryl of compound I and the heme substituents imply the use of an amino acid side chain or multiple side chains as redox mediators. ${ }^{49-51}$ Inspection of the 
environment surrounding propionate 2 (Fig. 2C) immediately identified Tyr145 as a possible secondary site of oxidation following the initial generation of a coproheme compound I. The side chain of Tyr 145 sits near to and forms an apparent H-bond with the carboxylate moiety of propionate 2, in a position analogous to the ascorbate binding site in APX (Fig. S1). ${ }^{8}$ This configuration suggested that Tyr145 might be well-positioned to be oxidized by the coproheme compound I (Scheme 2B), and that it may in fact act as the reactive species toward propionate 2. Consistent with that hypothesis, substitution of Tyr145 with Ser led to complete loss of coproheme decarboxylation. A concomitant large increase in catalase activity (Fig. 6) suggested that, in the absence of Tyr145, the enzyme readily forms $\mathrm{Fe}(\mathrm{IV})=\mathrm{O}$ (coproporphyrin + ) with the electron hole localized on the porphyrin.

Neutral tyrosyl radicals (TyrOa) are implicated in a variety of reactions, including those catalyzed by class I ribonucleotide reductase, ${ }^{52}$ photosystem II, ${ }^{53}$ galactose oxidase, ${ }^{54}$ and prostaglandin-H synthase. ${ }^{55}$ In each case, a metal center is involved in generating the tyrosyl radical, which then acts as the primary recipient of an electron or hydrogen atom from a substrate. In the case of prostaglandin-H synthase and other cyclooxygenases, the metal center is heme $b$, which oxidizes a nearby tyrosine side chain via a compound I intermediate. The bond dissociation free energy associated with $\mathrm{TyrO} / \mathrm{TyrOH}$ in these systems as well as phenolic model compounds can be quite high ${ }^{17,56}$ and, in the case of the tyrosine $\mathrm{Z}$ in photosystem II, thermodynamically sufficient for the oxidation of water. Net transfer of $\mathrm{H}$ from the propionate $\mathrm{C}_{\beta}-\mathrm{H}$ to Tyr145-O would result in a resonance-stabilized coproheme propionyl- $\mathrm{C}_{\beta}$ radical, suggesting a proportionally lower requisite driving force for carrying out the reaction. Though mutagenesis showed it was not essential for coproheme turnover by the decarboxylase, the side chain of Arg218 is well-positioned to shuttle propionate-derived protons from the active site. A similarly situated arginine residue obligately serves this function in the oxidation of ascorbate by APX (Fig. S1). ${ }^{10}$ Transfer of a second electron from the $\mathrm{C}_{\beta} \boldsymbol{\omega}$ through the porphyrin and to the coproheme $\mathrm{Fe}(\mathrm{IV})$ would result in the regeneration of $\mathrm{Fe}$ (III) and production of the vinyl and $\mathrm{CO}_{2}$ (Scheme $2 \mathrm{~B}$ ).

Decarboxylation at propionate 2 is followed by a second, slightly faster ${ }^{22} \mathrm{H}_{2} \mathrm{O}_{2}$-dependent reaction at propionate 4. Inspection of the environment surrounding this group identified three readily oxidizable aromatic residues in its vicinity (Tyr114, Trp198, Trp157) as well as a lysine (Lys149) which, like Arg218, could potentially act as an initial recipient or conduit for protons (Fig. 2E). Individual mutations at each of these residues showed that only Lys149 appeared to be essential for coproheme turnover. Substitution of this residue with alanine resulted in the accumulation of the three-propionate intermediate, harderoheme III (Scheme 1). This result suggested that harderoheme maintains the same position as the coproheme substrate, as predicted by solution state rR, and loss of the harderoheme-Lys 149 interaction specifically inhibits the decarboxylation of propionate $4 .{ }^{22}$ We therefore conclude that $\mathrm{H}_{2} \mathrm{O}_{2}$ activation by the harderoheme-decarboxylase proceeds in a similar environment as the coproheme complex, though the $\mathrm{Fe}(\mathrm{III}) /(\mathrm{II})$ reduction potential $^{22}$ and the degree of distal pocket interaction with the bound substrate (Fig. 4) have diminished. The pronounced increase in catalase activity in the Lys149Ala mutant likewise suggests that it reacts with $\mathrm{H}_{2} \mathrm{O}_{2}$ to form $\mathrm{Fe}(\mathrm{IV})=\mathrm{O}$ (harderoporphyrin $\square+$ ). 
If this intermediate forms during catalytic turnover, then Tyr114, Trp198, and Trp157 all appear reasonably positioned to form Tyr-O $\mathbf{n}$ or Trp + radicals by filling the electron hole on (harderoporphyrin + ). The side chain could then mediate a reaction with propionate 4 ,

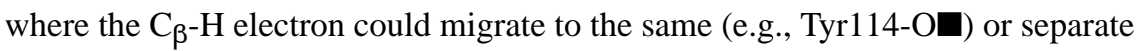
destinations. In the latter case, Lys149 could serve an essential role as the proton acceptor in a proton coupled electron transfer. However, mutation of any of these aromatic residues independently had virtually no effect on the efficiency of either propionate decarboxylation. This suggests one of two interpretations. First, it is possible that radical density is spread over two or more of these residues, and that the others can compensate in the event that one is lost. Alternatively, Tyr145-O could act as the enzyme's sole redox mediator toward both propionates 2 and 4 . Though the latter is farther from Tyr145, net proton coupled electron transfers can occur across long distances. The reactive Tyr-O $\mathrm{O}$ in ribonucleotide reductases sets an impressive precedent, reacting with a cysteine-SH over 35 A away. ${ }^{52}$ Supporting this hypothesis in part, we noted that reaction of the Tyr145Ser-coproheme complex with $\mathrm{H}_{2} \mathrm{O}_{2}$ yielded neither harderoheme nor heme $b$, suggesting that both decarboxylations are impaired by this substitution. Moreover, when a complex of the same mutant was prepared with exogenously supplied harderoheme III, its reaction with $\mathrm{H}_{2} \mathrm{O}_{2}$ also yielded no heme $b$. Tyr145 is clearly essential for both propionate oxidations, though whether it acts as a radical mediator in either case is still unknown. How Tyr145 would form the Tyr-O radical in the absence of the conduit provided by propionate 2 , once it has converted to vinyl, is an open question, though we note that there is a clear kinetic preference for oxidizing propionate 2 first. This oxidation could be facilitated by the existence of the propionate-Tyr145 interaction.

The chemistry, spectroscopy, and structure reported here constitute an internally consistent account of function and mechanism in this class of decarboxylases. Tyr145 and Lys149 are H-bonded to the reactive propionates 2 and 4, respectively, and play essential roles in the reactivity and regioselectivity of propionates 2 and 4 toward oxidation. These nonbonded interactions differ markedly from those recently reported for the Listeria monocytogenes enzyme ( $L m H$ HemQ), in which coproheme III is oriented such that propionates 2 and 7 are oriented toward the surface of the enzyme while propionates 4 and 6 are directed into the pocket. In the $L m H$ HemQ structure, propionate 2 is H-bonded to Gln187, propionate 4 is $\mathrm{H}$ bonded to Tyr147, and the unreactive propionate 6 is H-bonded to Lys151 (comparable to Gln185, Tyr145 and Lys149, respectively, in the $S a$ enzyme). Though there are some differences in crystallization parameters ( $G s$ decarboxylase crystals were grown at $\mathrm{pH} 7.5$, for example, whereas the $L m$ decarboxylase crystals were obtained at $\mathrm{pH} 9.0$ ) the reasons for this different coproheme orientation are unclear. Though it seems unlikely that homologous decarboxylases from different organisms would utilize different coproheme orientations, this possibility cannot be eliminated at this time. More in-depth comparison of the two coproheme-decarboxylase structures is not possible at the time of writing because the $L m H e m Q$ structure has yet to be released. ${ }^{57}$

OleT and the coproheme decarboxylase described here are atypical for using $\mathrm{H}_{2} \mathrm{O}_{2}$ as the cosubstrate in an oxidative decarboxylation. Coproheme decarboxylase is further distinguished by its evident use of an extended relay of propionate and side chain mediators to convey electrons and protons away from its pair of substrates and toward $\mathrm{H}_{2} \mathrm{O}_{2}$, ultimately 
releasing $\mathrm{CO}_{2}$. This use of the metalloporphyrin as a primary site of oxidation, in conjunction with a series of stably positioned mediators, also suggests an alternative approach for synthetic or semi-synthetic catalysis of the oxidative decarboxylation of fatty acids to generate alkenes.

\section{Supplementary Material}

Refer to Web version on PubMed Central for supplementary material.

\section{Acknowledgments}

\section{Funding Sources}

This work was supported by funding from the National Institutes of Health, General Medical Sciences R01GM090260 (J.L.D.) and R15GM114787 (G.S.L.-R.). Structural work was supported by the U.S. Department of Energy, Office of Science, Office of Basic Energy Sciences, under Award Number DE-FG02-04ER15563 to J.W.P.

We thank the National Institutes of Health for supporting this work. Additionally, we thank the Department of Energy for support of the structural work, carried out at the Stanford Synchrotron Radiation Laboratory at the Stanford Linear Accelerator Center. This work will be presented at the Gordon Research Conference on Metals in Biology and at the ASBMB national meeting, 2017.

\section{ABBREVIATIONS}

\begin{tabular}{ll} 
ABTS & $2,2^{\prime}$-Azinobis [3-ethylbenzothiazoline-6-sulfonic acid]-diammonium salt \\
ACN & acetonitrile \\
APX & ascorbate peroxidase \\
CCP & cytochrome $c$ peroxidase \\
Cld & Chlorite dismutase \\
Da & Dechloromonas aromatica \\
ESI & electrospray ionization \\
Gs & Geobacillus stearothermophilus \\
HPLC & High Performance Liquid Chromatography \\
HRP & horseradish peroxidase \\
LnP & lignin peroxidase \\
MS & mass spectrometry \\
NMR & nuclear magnetic resonance \\
Nd & Nitrospira defluvii \\
PAA & peracetic acid \\
QTOF & quadrupole time-of-flight \\
\hline
\end{tabular}




$\begin{array}{ll}\text { rR } & \text { resonance Raman } \\ \text { Sa } & \text { Staphyloccocus aureus } \\ \text { TFA } & \text { trifluoroacetic acid }\end{array}$

LmHemQ Listeria monocytogenes decarboxylase

rR resonance Raman

\section{References}

1. Traylor, TG., Traylor, PS. Reactions of dioxygen and its reduced forms with heme proteins and model porphyrin complexes. In: Valentine, JS.Foote, CS.Greenberg, A., Liebman, JF., editors. Active Oxygen in Biochemistry. Springer Netherlands; 1995. p. 84-187.

2. Dunford, HB. Heme Peroxidases. Wiley-VCH; New York: 1999.

3. Ortiz de Montellano, PR. Cytochrome P450: Structure, Mechanism and Biochemistry. 3. Kluwer Academic/Plenum; New York: 2005.

4. Rittle J, Green MT. Science. 2010; 330:933-7. [PubMed: 21071661]

5. Hammes-Schiffer S. J Am Chem Soc. 2015; 137:8860-8871. [PubMed: 26110700]

6. Reece SY, Hodgkiss JM, Stubbe J, Nocera DG. Philos Trans R Soc Lond B Biol Sci. 2006; 361:1351-1364. [PubMed: 16873123]

7. Macdonald IK, Badyal SK, Ghamsari L, Moody PC, Raven EL. Biochemistry. 2006; 45:7808-7817. [PubMed: 16784232]

8. Sharp KH, Mewies M, Moody PC, Raven EL. Nat Struct Biol. 2003; 10:303-307. [PubMed: 12640445]

9. Warren JJ, Mayer JM. J Am Chem Soc. 2011; 133:8544-8551. [PubMed: 21524059]

10. Efimov I, Badyal SK, Metcalfe CL, Macdonald I, Gumiero A, Raven EL, Moody PC. J Am Chem Soc. 2011; 133:15376-15383. [PubMed: 21819069]

11. Gumiero A, Metcalfe CL, Pearson AR, Raven EL, Moody PC. J Biol Chem. 2011; 286:1260-1268. [PubMed: 21062738]

12. (a) Poulos TL. Chem Rev. 2014; 114:3919-3962. [PubMed: 24400737] (b) Cherifi G, Baxter EL, Doukov T, Cohen AE, McPhillips SE, Song J, Meharenna YT, Soltis SM, Poulos TL. Proc Natl Acad Sci USA. 2016; 112:1226-1231.

13. Pelletier H, Kraut J. Science. 1992; 258:1748-1755. [PubMed: 1334573]

14. Choinowski T, Blodig W, Winterhalter KH, Piontek K. J Mol Biol. 1999; 286:809-827. [PubMed: 10024453]

15. Colin J, Wiseman B, Switala J, Loewen P, Ivancich A. J Am Chem Soc. 2009; 131:8557-8563. [PubMed: 19530730]

16. Sivaraja M, Goodin DB, Smith M, Hoffman BM. Science. 1989; 245:738-740. [PubMed: 2549632]

17. Tommos C, Skalicky JJ, Pilloud DL, Wand AJ, Dutton PL. Biochemistry. 1999; 38:9495-9507. [PubMed: 10413527]

18. Guallar V. J Phys Chem B. 2008; 112:13460-13464. [PubMed: 18816089]

19. Grant JL, Mitchell ME, Makris TM. Proc Natl Acad Sci USA. 2016; 113:10049-10054. [PubMed: 27555591]

20. Dailey H, Gerdes S, Dailey T, Burch J, Phillips J. Proc Natl Acad Sci USA. 2015; 112:2210-2215. [PubMed: 25646457]

21. Celis AI, Streit BR, Moraski GC, Kant R, Lash TD, Lukat-Rodgers GS, Rodgers KR, DuBois JL. Biochemistry. 2015; 54:4022-4032. [PubMed: 26083961]

22. Streit BR, Celis AI, Shisler K, Rodgers KR, Lukat-Rodgers GD, DuBois JL. Biochemistry. 
23. Gilski, M., Borek, D., Chen, Y., Collart, F., Joachimiak, A., Otwinowski, Z. [accessed Dec 7, 2016] RCSB Protein Data Bank. http://www.rcsb.org/pdb/home/home.doPDB ID 1T0T, released Aug 4, 2004

24. Gonzalez, A., Tsai, Y. [accessed May 1, 2016] http://smb.slac.stanford.edu/facilities/software/xds/ \#autoxds_script

25. McCoy AJ, Grosse-Kunstleve RW, Adams PD, Winn MD, Storoni LC, Read RJ. J Appl Crystallogr. 2007; 40:658-674. [PubMed: 19461840]

26. Winn MD, Ballard CC, Cowtan KD, Dodson EJ, Emsley P, Evans PR, Keegan RM, Krissinel EB, Leslie AG, McCoy A, McNicholas SJ, Murshudov GN, Pannu NS, Potterton EA, Powell HR, Read RJ, Vagin A, Wilson KS. Acta Crystallogr D Biol Crystallogr. 2011; 67:235-42. [PubMed: 21460441]

27. Adams PD, Afonine PV, Bunkoczi G, Chen VB, Davis IW, Echols N, Headd JJ, Hung LW, Kapral GJ, Grosse-Kunstleve RW, McCoy AJ, Moriarty NW, Oeffner R, Read RJ, Richardson DC, Richardson JS, Terwilliger TC, Zwart PH. Acta Crystallogr D Biol Crystallogr. 2010; 66:213-21. [PubMed: 20124702]

28. Mayfield JA, Hammer ND, Kurker RC, Chen TK, Ojha S, Skaar EP, DuBois JL. J Biol Chem. 2013; 288:23488-504. [PubMed: 23737523]

29. Celis A, DuBois J. Arch Biochem Biophys. 2015; 574:3-17. [PubMed: 25778630]

30. Goblirsch B, Kurker RC, Streit BR, Wilmot CM, DuBois JL. J Mol Biol. 2011; 408:379-398. [PubMed: 21354424]

31. Hofbauer S, Dalla Sega M, Scheiblbrandner S, Jandova Z, Schaffner I, Mlynek G, Djinovic-Carugo K, Battistuzzi G, Furtmuller PG, Oostenbrink C, Obinger C. Biochemistry. 2016; 55:5398-5412. [PubMed: 27599156]

32. Hofbauer S, Howes BD, Flego N, Pirker KF, Schaffner I, Mlynek G, Djinović-Carugo K, Furtmuller PG, Smulevich G, Obinger C. Biosci Rep. 2016; 36:e00312. [PubMed: 26858461]

33. Choudhury K, Sundaramoorthy M, Hickman A, Yonetani T, Woehl E, Dunn MF, Poulos TL. J Biol Chem. 1994; 269:20239-20249. [PubMed: 8051115]

34. Poulos, TL., Fenna, RE. Metal Ions In Biological Systems. Vol. 30. Wiley VCH; New York: 1994. Peroxidases - Structure, Function, And Engineering.

35. Blanc B, Mayfield JA, McDonald CA, Lukat-Rodgers GS, Rodgers KR, DuBois JL. Biochemistry. 2012; 51:1895-1910. [PubMed: 22313119]

36. Singh R, Grigg JC, Armstrong Z, Murphy MEP, Eltis LD. J Biol Chem. 2012; 287:10623-10630. [PubMed: 22308037]

37. Erman JE, Vitello LB, Miller MA, Kraut J. J Am Chem Soc. 1992; 114:6592-6593.

38. Layer G, Pierik AJ, Trost M, Rigby SE, Leech HK, Grage K, Breckau D, Astner I, Jaensch L, Heathcote P, Warren MJ, Heinz DW, Jahn D. J Biol Chem. 2006; 281:15727-34. [PubMed: 16606627]

39. Draganova EB, Adrian SA, Lukat-Rodgers GS, Keutcha CS, Schmitt MP, Rodgers KR, Dixon DW. J Biol Inorg Chem. 2016; 21:875-86. [PubMed: 27561288]

40. Spiro TG, Soldatova AV, Balakrishnan G. Coord Chem Rev. 2013; 257:511-527. [PubMed: 23471138]

41. Lukat-Rodgers GS, Rodgers KR, Caillet-Saguy C, Izadi-Pruneyre N, Lecroisey A. Biochemistry. 2008; 47:2087-2098. [PubMed: 18205408]

42. Spiro TG, Wasbotten IH. J Biol Inorg Chem. 2005; 99:34-44.

43. Blanc B, Mayfield JA, McDonald CA, Lukat-Rodgers GS, Rodgers KR, DuBois JL. Biochemistry. 2012; 51:1895-1910. [PubMed: 22313119]

44. Hofbauer S, Howes BD, Flego N, Pirker KF, Schaffner I, Mlynek G, Djinovic-Carugo K, Furtmueller PG, Smulevich G, Obinger C. Biosci Rep. 2016; 36:e00312. [PubMed: 26858461]

45. Goblirsch BR, Streit BR, DuBois JL, Wilmot CM. J Biol Inorg Chem. 2010; 15:879-888. [PubMed: 20386942]

46. Streit BR, Blanc B, Lukat-Rodgers GS, Rodgers KR, DuBois JL. J Am Chem Soc. 2010; 132:5711-5724. [PubMed: 20356038] 
47. Hofbauer S, Gruber C, Pirker K, Schaffner I, Furtmuller P, Obinger C, Hagmuller A, Gysel K, Mlynek G, Kostan J, Djinovic-Carugo K, Bellei M, Battistuzzi G, Daims H. J Biol Inorg Chem. 2014; 19:S253-S253.

48. Grant JL, Hsieh CH, Makris TM. J Am Chem Soc. 2015; 137:4940-4943. [PubMed: 25843451]

49. Zheng YM, Baer BR, Kneller MB, Henne KR, Kunze KL, Rettie AE. Biochem. 2003; 42:46014906. [PubMed: 12693958]

50. Colas C, Ortiz de Montellano PR. Chem Rev. 2003; 103:2305-2332. [PubMed: 12797831]

51. Brown KR, Brown BM, Hoagland E, Mayne CL, Hegg EL. Biochemistry. 2004; 43:8616-8624. [PubMed: 15236569]

52. Stubbe J, Nocera DG, Yee CS, Chang MCY. Chem Rev. 2003; 103:2167-2201. [PubMed: 12797828]

53. Okamura MY, Paddock ML, Graige MS, Feher G. Biochim Biophys Acta. 2000; 1458:148-163. [PubMed: 10812030]

54. Whittaker JW. Chem Rev. 2003; 103:2347-2363. [PubMed: 12797833]

55. Tsai AL, Kulmacz RJ, Palmer G. J Biol Chem. 1995; 270:10503-10508. [PubMed: 7737984]

56. Warren JJ, Tronic TA, Mayer JM. Chem Rev. 2010; 110:6961-7001. [PubMed: 20925411]

57. Hofbauer, S., Mlynek, G., Millazo, L., Puhringer, D., Maresch, D., Schaffner, I., Furtmuller, PG., Smulevich, G., Djinović-Carugo, K., Obinger, C. [accessed Oct 30, 2016] Hydrogen Peroxide Mediated Conversion of Coproheme to Heme $b$ by HemQ. Lessons from the First Crystal Structure and Kinetic Studies. FEBS J. [Online early access]Published Online: Nov 14, 2016. http://onlinelibrary.wiley.com/wol1/doi/10.1111/febs.13930/abstract 

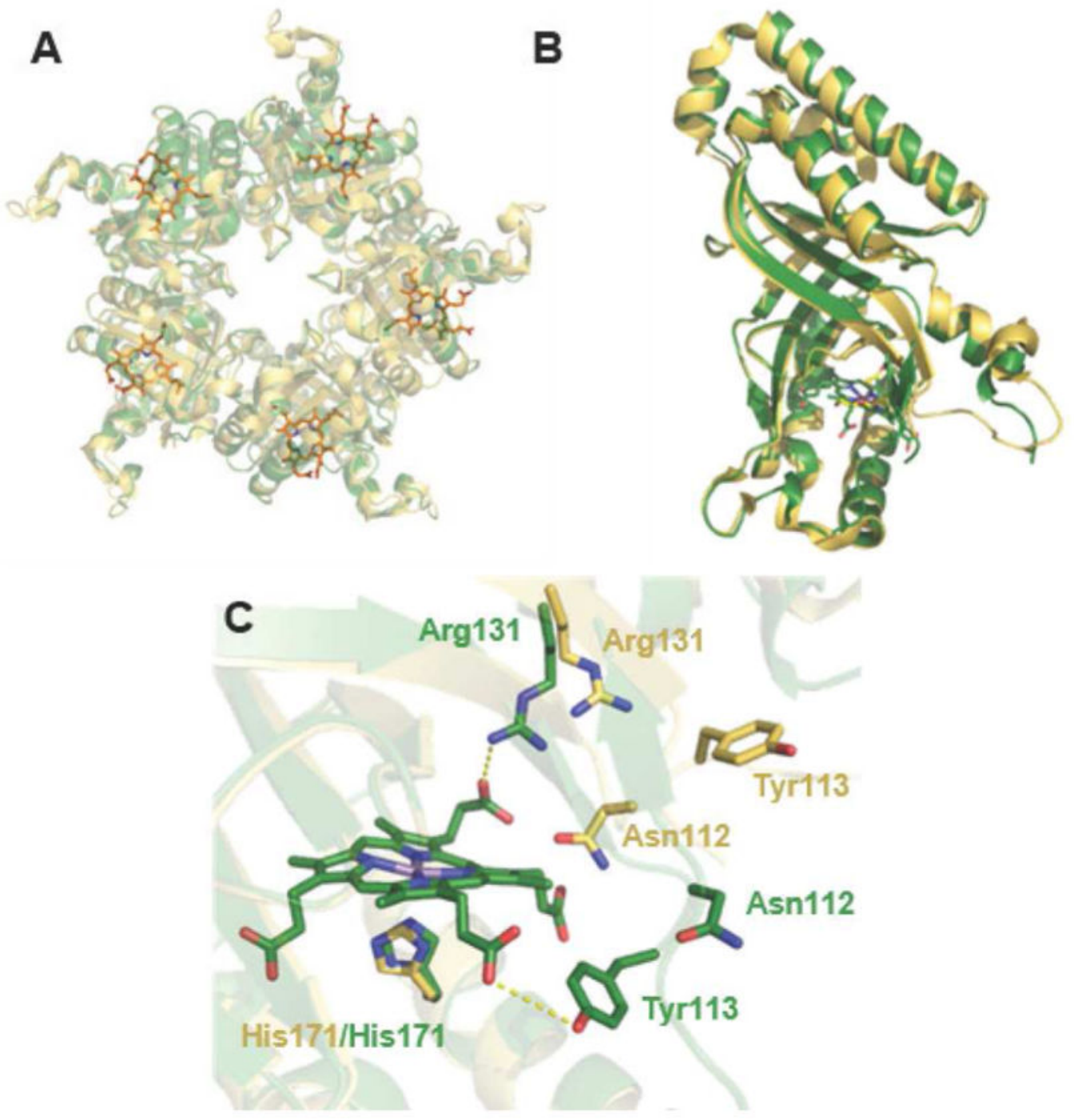

Figure 1. Superposition of the apo and ligand-bound forms of coproheme decarboxylase illustrate the effects of tetrapyrrole binding

A. The Mn(III)-coproporphyrin-bound decarboxylase homopentamer is shown in green with the bound $\mathrm{Mn}(\mathrm{III})$ - coproporphyrin ligands as sticks (orange) (5T2K) and the ligand-free structure in yellow (1T0T). The view is down the pseudo- $\mathrm{C}_{5}$ axis with the coprohemecontaining domains oriented toward the viewer. B. Superimposition of an individual subunit of coproheme decarboxylase in the apo (yellow) and ligand-bound (green) forms.

Differences are localized around a flexible loop near residues 111-120 and the Mn(III)coproporphyrin binding site. C. Close-up view of the Mn(III)-coproporphyrin binding site, illustrating prominent shifts in the positions of side chains for Asn112, Tyr113, and Arg131 in the apo- (yellow) and ligand-bound (green) forms. 
A

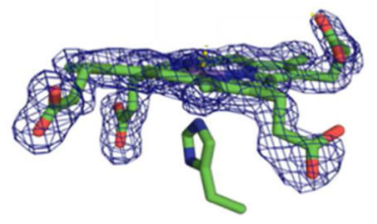

B

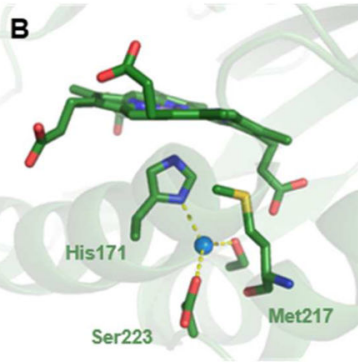

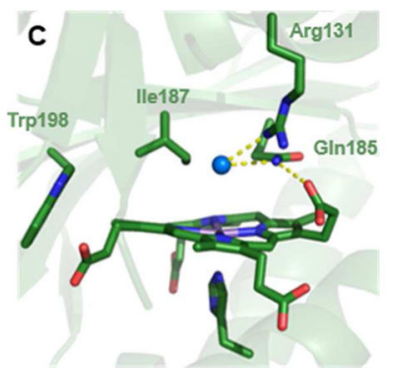
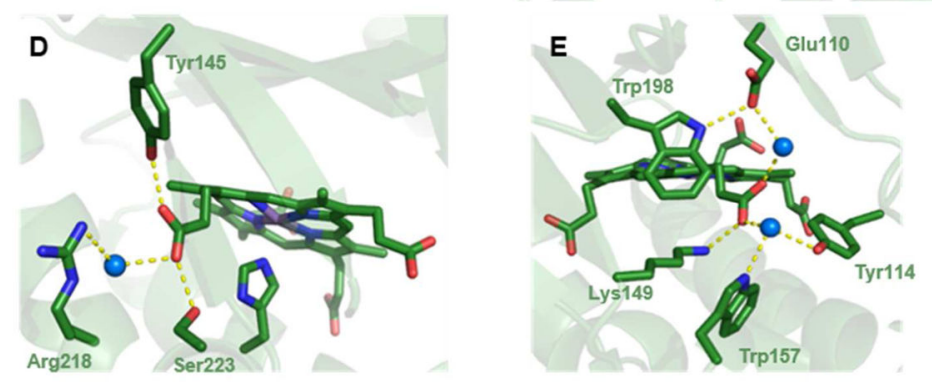

Figure 2. The structure of the coproheme binding site in coproheme decarboxylase has important implications for the chemical mechanism

A. View of the Mn-coproheme in subunit $\mathrm{B}$ with $\mathrm{Fo}-\mathrm{Fc}$ omit electron density map contoured at $3 \sigma$. B. The tetrapyrrole is slightly ruffled, with the two reactive propionates ( 2 and 4 ) below its approximate plane. A close-up view of the His171 ligand in the (proximal) pocket beneath the substrate analog shows that it binds to the metal through the imidazole- $\mathrm{N}_{\varepsilon}$. The imidazole- $\mathrm{N}_{\delta}$ forms an apparent hydrogen bond to a water molecule, which is itself hydrogen bonded to Ser223 and Asp220. C. The distal region above the coproheme plane is shown, highlighting the pair of unreactive propionates. The R131 side chain is part of a hydrogen bonding network involving propionate $6, G \ln 185$, and a water molecule that occupies a position close to where the terminal oxygen of $\mathrm{Fe}-\mathrm{OOH}$ might reside. The residue immediately over the coproheme plane is Ile187. The environment surrounding the reactive propionates 2 and 4 is shown in $\mathrm{D}$ and $\mathrm{E}$, respectively. 


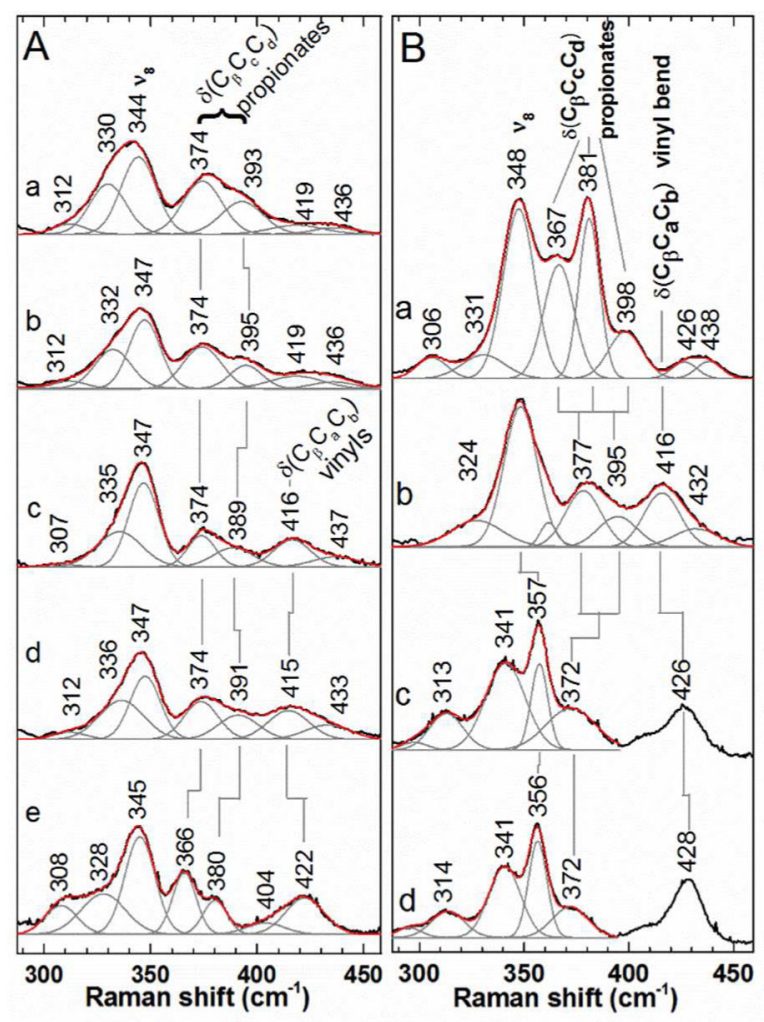

Figure 3. Low frequency $r R$ spectra report on the core and peripheral environment of hemes bound to decarboxylases

A) The 406.7-nm excited rR spectra of ferric forms of a) coproheme: Sa decarboxylase, b) coproheme: $G s$ decarboxylase c) heme $b: S a$ decarboxylase, d) heme $b: G s$ decarboxylase, and e) $\mathrm{DaCld}(\mathrm{R} 183 \mathrm{Q})$. Ferric samples were in $100 \mathrm{mM}$ potassium phosphate at $\mathrm{pH} 7.4$. B) Soretexcited rR spectra of CO complexes of a) coproheme: $S a$ decarboxylase, b) heme $b: S a$ decarboxylase, c) WT $D a C l d$, and d) $D a C l d(\mathrm{R} 183 Q)$. Both $D a C l d$ enzymes contain heme $b$. Spectra of CO samples in $100 \mathrm{mM}$ potassium phosphate at $\mathrm{pH} 6.8$ were acquired with 413.1 $\mathrm{nm}$ excitation and $2 \mathrm{~mW}$ power at the sample. Original spectra, black; fit spectra, red; component bands making up the fit spectra, gray. 

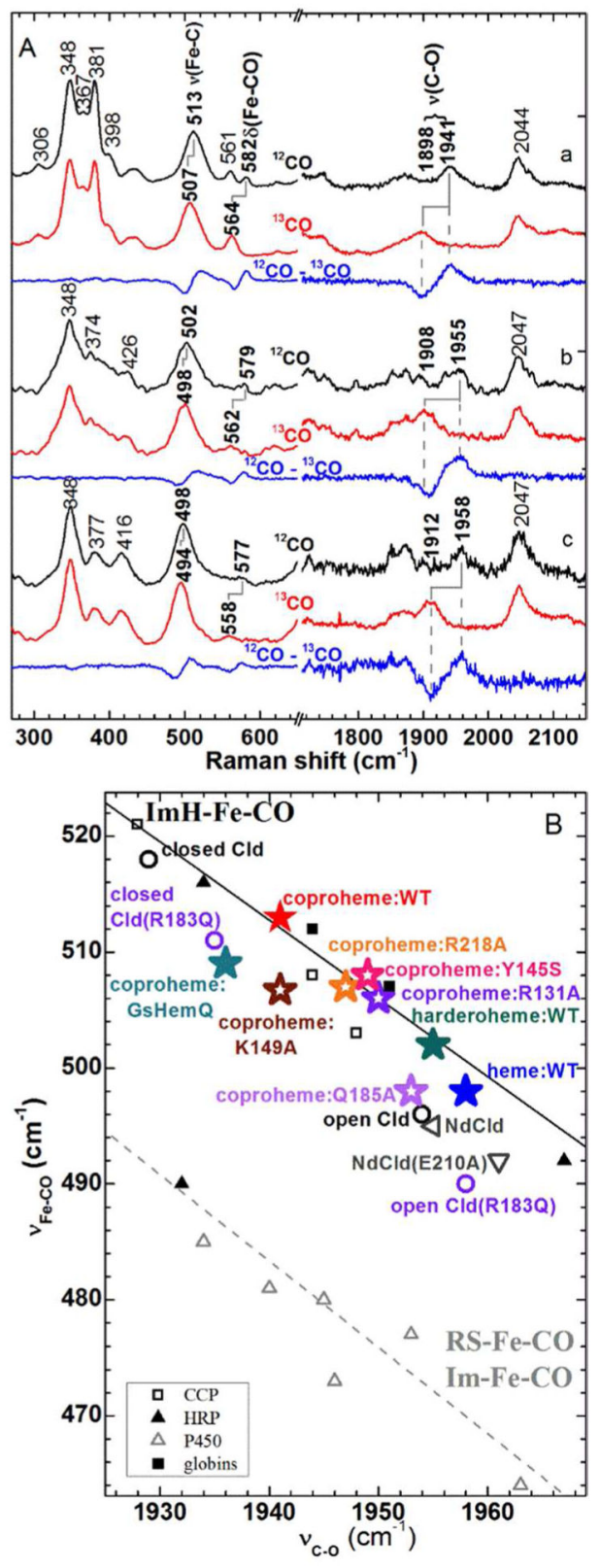

Figure 4. rR characterization of ferrous CO complexes of the $S a$ decarboxylase report on their proximal ligands and distal environments

A) Soret-excited rR spectra of the isotopomers of $\mathrm{CO}$ complexes of the decarboxylase bound to a) coproheme b) harderoheme III, and c) heme $b$ at $\mathrm{pH}$ 6.8. Spectra were acquired with $413.1 \mathrm{~nm}$ excitation and $2 \mathrm{~mW}$ power at the sample. ${ }^{12} \mathrm{CO}$ complex, black; ${ }^{13} \mathrm{CO}$ complex, red; difference spectra ${ }^{12} \mathrm{CO}-{ }^{13} \mathrm{CO}$, blue. B) Backbonding correlation plot of $\nu_{\mathrm{Fe}-\mathrm{C}}$ versus $v_{\mathrm{C}-\mathrm{O}}$ for ferrous carbonyls of heme proteins shows the dependences of their positions on axial ligation and distal pocket properties. The black line correlates $\mathrm{v}_{\mathrm{Fe}-\mathrm{C}}$ with $\mathrm{v}_{\mathrm{C}-\mathrm{O}}$ for sixcoordinate $\mathrm{Fe}-\mathrm{CO}$ adducts in which the sixth ligand is histidine (neutral imidazole). The gray dashed line represents six-coordinate $\mathrm{Fe}-\mathrm{CO}$ adducts in which the sixth ligand is a 
thiolate or and imidazolate. Points used for these lines are tabulated in Table S1 of reference 43. Data for $\mathrm{DaClds}$ and $\mathrm{NdClds}$ are from references 43 and 44, respectively. 

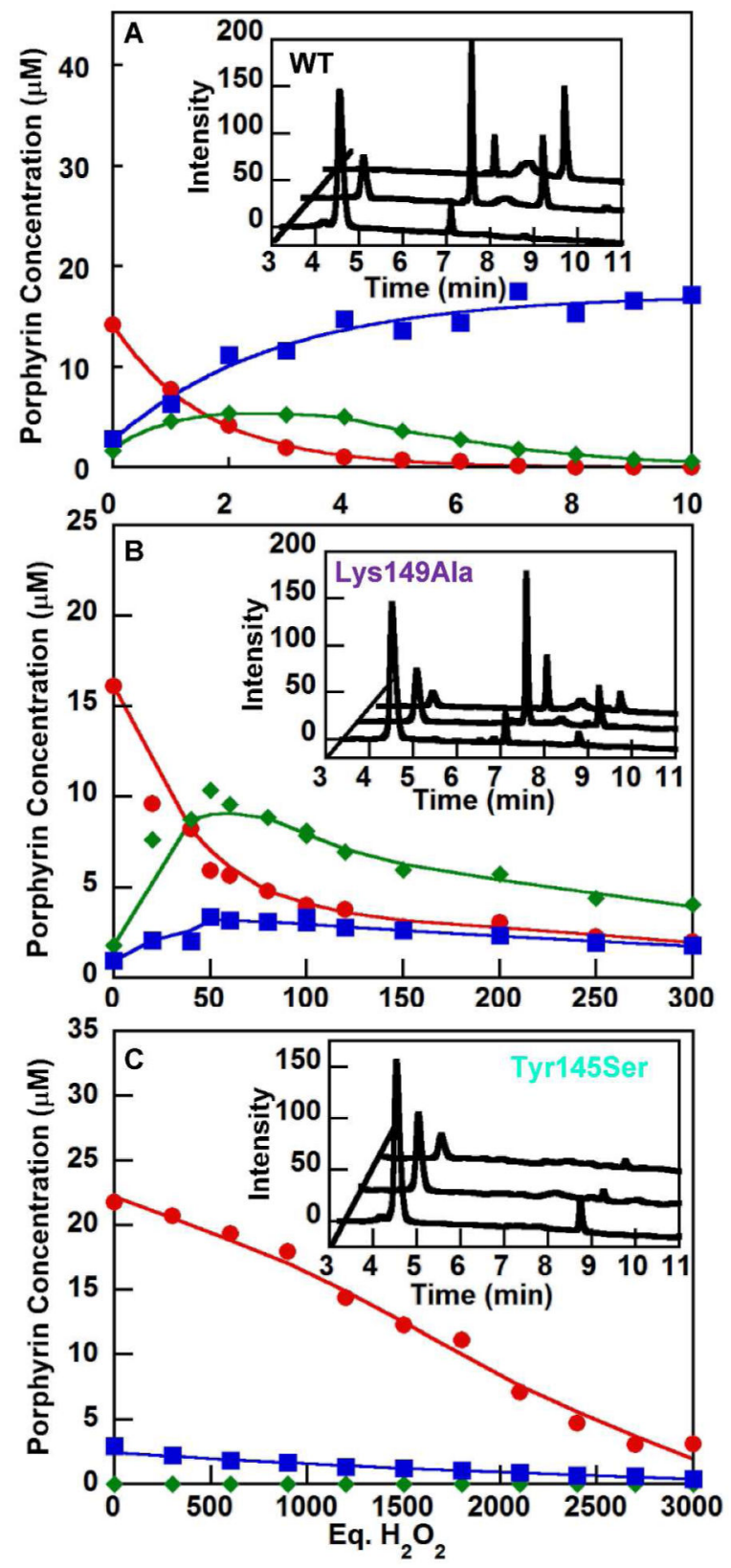

Figure 5. Mutations at Lys149 and Tyr145 prevent decarboxylation of one or both propionic acid substrates, respectively

Unreacted coproheme (red), harderoheme III intermediate (green) and the heme $b$ product (blue) of the coproheme decarboxylase reaction with increasing eq of $\mathrm{H}_{2} \mathrm{O}_{2}$ were quantified by HPLC for (top) WT enzyme and the mutants (center) Lys149Ala and (bottom)

Tyr145Ser. HPLC traces illustrating the starting material, observable intermediates, and final products are shown as insets. Retention times for unreacted coproheme, the harderoheme III intermediate, and heme $b$ product were $4.8,7.1$ and 8.9 min, respectively. 

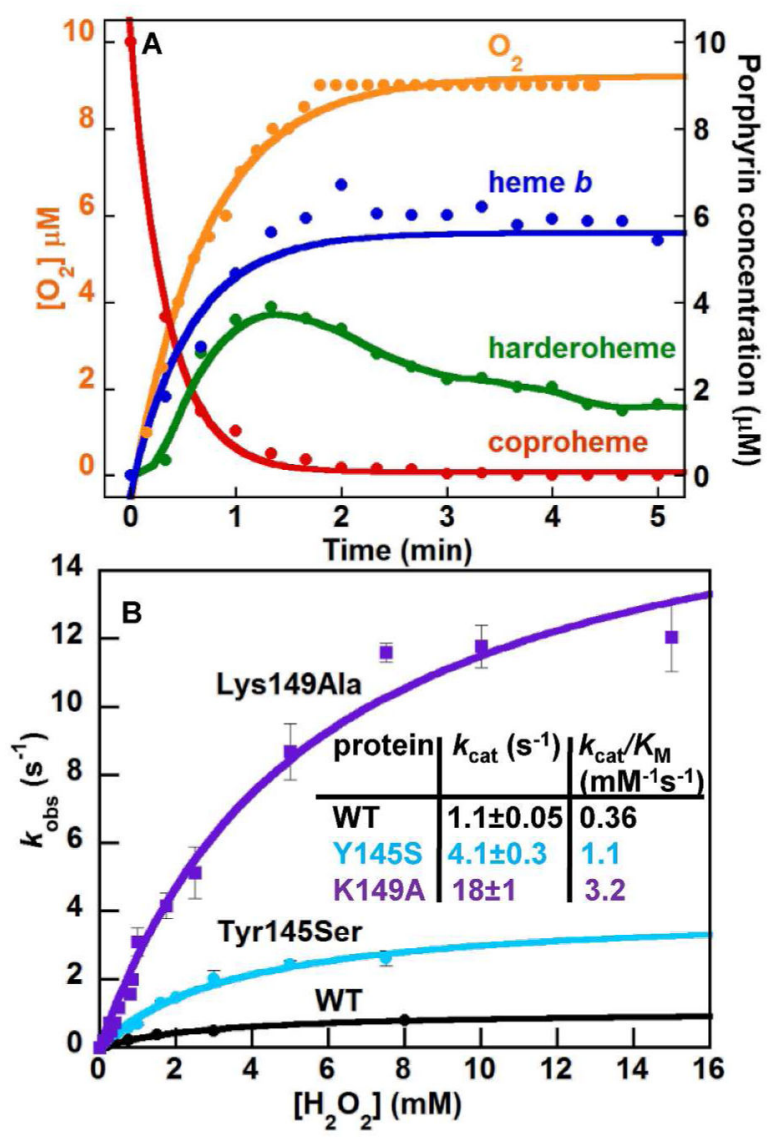

Figure 6. The catalase activity of coproheme decarboxylase is strongly enhanced in the Lys149Ala and Tyr145Ser mutants

(A) The progress of the coproheme decarboxylase reaction over time [coproheme (red), harderoheme III (green), heme $b$ (blue)] measured previously ${ }^{22}$ is shown superimposed on the time course for $\mathrm{O}_{2}$ production (orange) (10 $\mu \mathrm{M}$ enzyme-coproheme, $120 \mu \mathrm{M} \mathrm{H}_{2} \mathrm{O}_{2}, 50$ $\mathrm{mM} \mathrm{KPi}, \mathrm{pH} 7.4,25^{\circ} \mathrm{C}$ ). The generation of $\sim 10 \mu \mathrm{M} \mathrm{O}_{2}$ via the catalase reaction suggests that $\sim 20 \mu \mathrm{M} \mathrm{H}_{2} \mathrm{O}_{2}$ was consumed during the same time window in which coproheme converted to heme $b$. (B) Initial rates of $\mathrm{O}_{2}$ production were measured as a function of $\left[\mathrm{H}_{2} \mathrm{O}_{2}\right]$ and fit to eqn (5) for the WT (black), Tyr145Ser (cyan), and Lys149Ala (purple) decarboxylases. The resulting steady state parameters describing catalase activity are tabulated in the inset. 

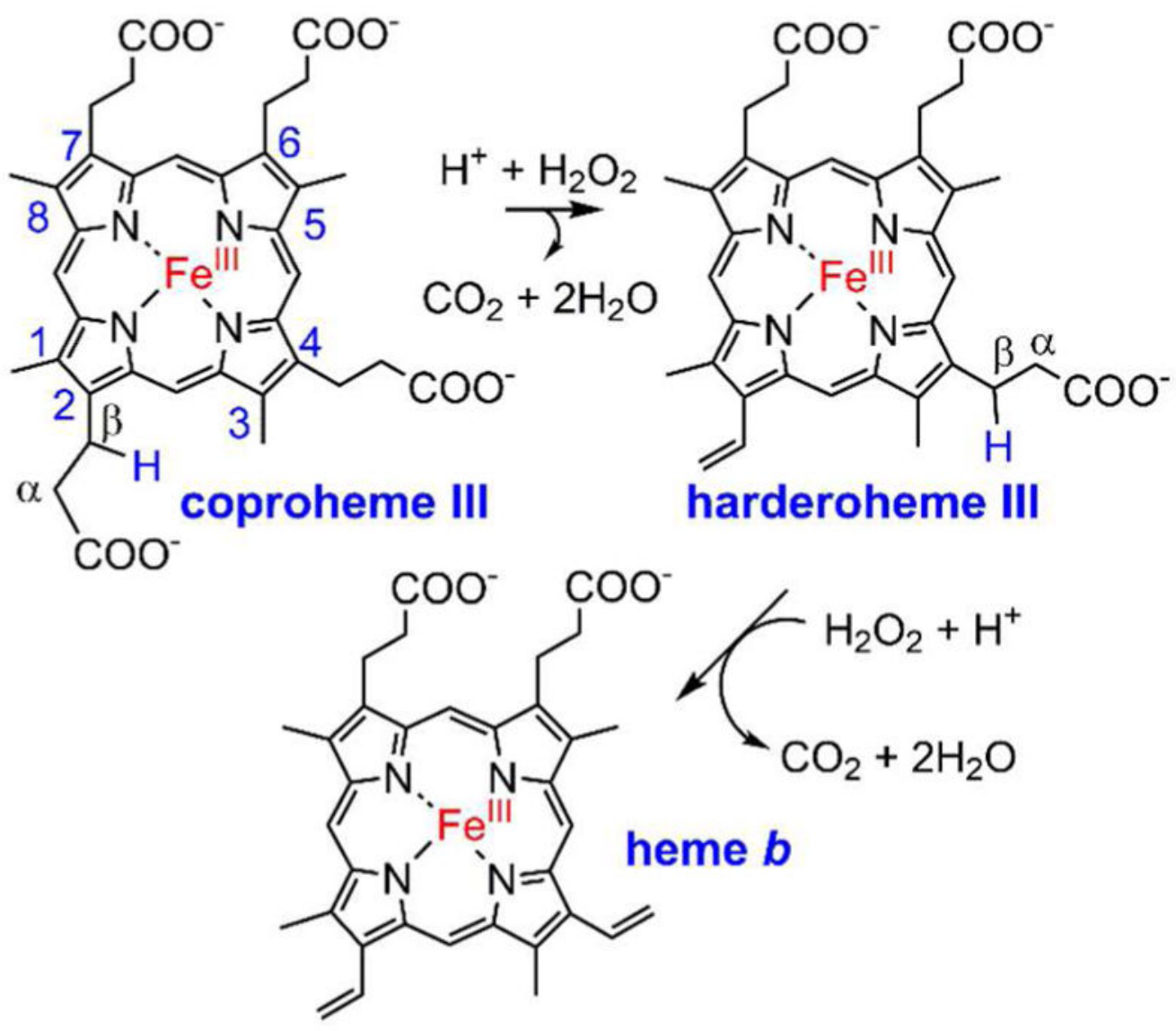

Scheme 1. Reaction catalyzed by coproheme decarboxylase $e^{\dagger}$

${ }^{\dagger} \mathrm{Net}$ loss of $2 \mathrm{e}^{-}+\mathrm{H}^{+}$from the $\mathrm{Ca}-\mathrm{C} \beta$ bond of each propionate occurs along with decarboxylation. Involvement of $\mathrm{Fe}(\mathrm{III}), \mathrm{H}_{2} \mathrm{O}_{2}$, and harderoheme III in the reaction scheme was previously verified. ${ }^{21,22}$ The porphyrin species are drawn in their expected protonation states at $\mathrm{pH} 7$. 

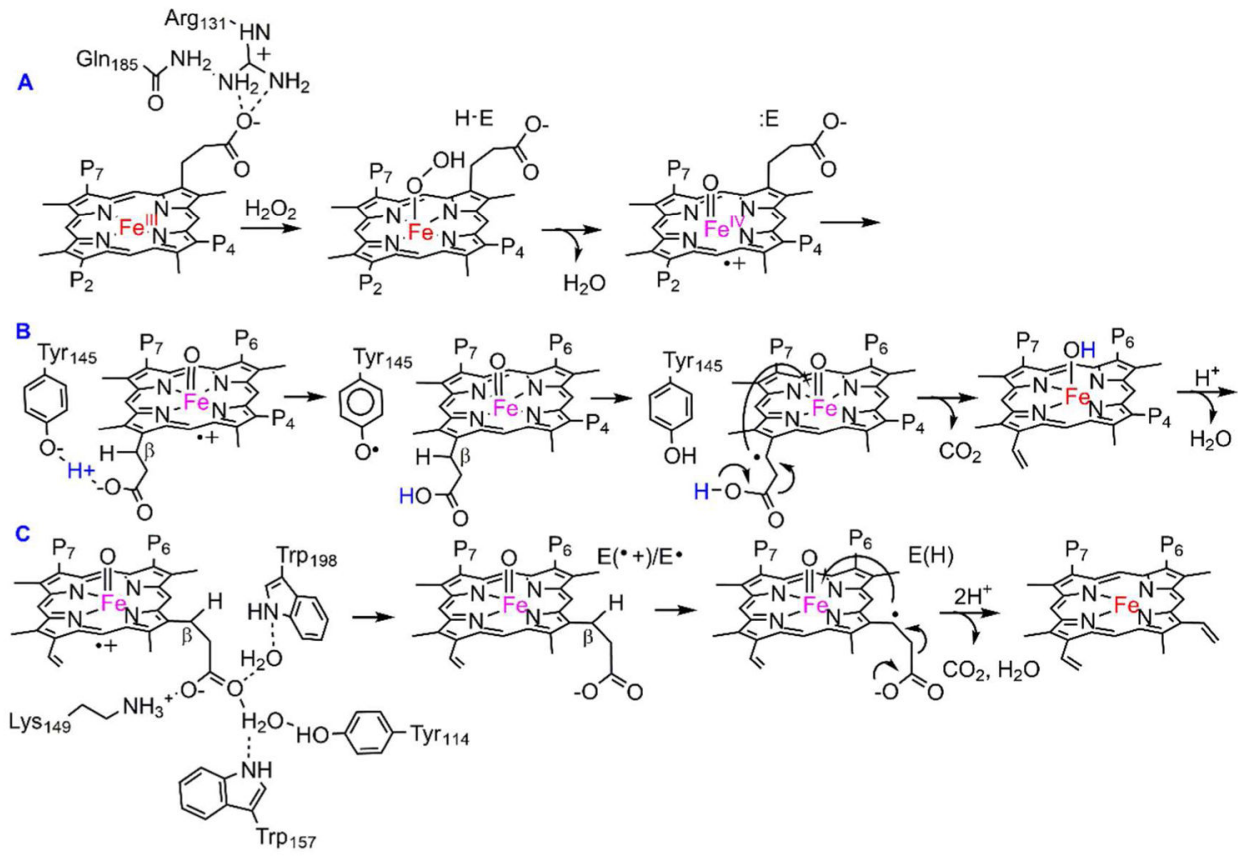

Scheme 2. Proposed mechanisms consistent with the available data ${ }^{\dagger}$

${ }^{\dagger}$ A. Formation of $\mathrm{Fe}(\mathrm{IV})=\mathrm{O}$ (coproporphyrin + ) (coproheme compound I) (E = enzyme; $\mathrm{Fe}(\mathrm{III})$ in red and $\mathrm{Fe}(\mathrm{IV})$ in purple). B. Oxidative decarboxylation of propionate 2 requires Tyr145. The neutral Tyr145-O radical is depicted abstracting hydrogen $(\mathrm{H} \mathbf{\square})$ from the propionate $\mathrm{C}_{\beta}$, though this is hypothetical. Transfer of an electron and proton to the ferryl of Compound II then leads to the ferric-OH complex of harderoheme III, from which water can ultimately depart. C. Following another round of $\mathrm{H}_{2} \mathrm{O}_{2}$-activation analogous to (A), a second $\mathrm{Fe}(\mathrm{IV})=\mathrm{O}$ (harderoporphyrin $\mathbf{-}$ ) complex forms. Three possible redox-active amino acids are connected to propionate 4 via hydrogen bonding through water molecules, though only Lys 149 appeared to play a role decarboxylating propionate 4 . The identity of the mediator for proton coupled electron transfer from the propionate (designated E+ or E $\mathbf{E}$ ) is unclear. Net uptake of $\mathrm{H}$ by the enzyme is designated via $\mathrm{E}(\mathrm{H})$. 